\title{
Enhancing tumor specific immune responses by transcutaneous vaccination
}

\author{
Hanadi Saliba, Béatrice Heurtault, Hasnaa Bouharoun-Tayoun, Vincent \\ Flacher, Benoît Frisch, Sylvie Fournel \& Soulaima Chamat
}

To cite this article: Hanadi Saliba, Béatrice Heurtault, Hasnaa Bouharoun-Tayoun, Vincent Flacher, Benoît Frisch, Sylvie Fournel \& Soulaima Chamat (2017): Enhancing tumor specific immune responses by transcutaneous vaccination, Expert Review of Vaccines, DOI:

10.1080/14760584.2017.1382357

To link to this article: http://dx.doi.org/10.1080/14760584.2017.1382357

Accepted author version posted online: 22

Sep 2017.

Submit your article to this journal $₫$

Q View related articles $\longleftarrow$

View Crossmark data $\nearrow$ 
Review

\section{Enhancing tumor specific immune responses by transcutaneous vaccination}

Hanadi Saliba (1, 2), Béatrice Heurtault (1), Hasnaa Bouharoun-Tayoun (2), Vincent Flacher (3), Benoît Frisch (1), Sylvie Fournel (1), Soulaima Chamat $(2,4)$ *

${ }^{1}$ Biovectorology team, Laboratory of Design and Application of bioactive molecules, UMR 7199CNRS / University of Strasbourg, Faculty of Pharmacy, 74 route du Rhin, 67401 Illkirch Cedex, France

${ }^{2}$ Laboratory of Immunology, Faculty of Public Health, Lebanese University, Fanar, Lebanon. ${ }^{3}$ Laboratory of Immunopathology and Therapeutic Chemistry, CNRS UPR 3572/Laboratory of Excellence MEDALIS, Institut de Biologie Moléculaire et Cellulaire, Strasbourg, France. ${ }^{4}$ Faculty of Medicine, Lebanese University, Hadath, Lebanon

*Corresponding author:

Soulaima Chamat

Faculty of Medicine, codirector of Laboratory of Immunology, Faculty of Public Health, Lebanese University.

E-mail: schamat@ul.edu.lb 


\section{Abstract}

\section{Introduction}

Our understanding of the involvement of the immune system in cancer control has increased over recent years. However, the development of cancer vaccines intended to reverse tumorinduced immune tolerance remains slow as most current vaccine candidates exhibit limited clinical efficacy. The skin is particularly rich with multiple subsets of dendritic cells (DCS) that are involved to varying degrees in the induction of robust immune responses. Transcutaneous administration of cancer vaccines may therefore harness the immune potential of these DCs, however, this approach is hampered by the impermeability of the stratum corneum. Innovative vaccine formulations including various nanoparticles, such as liposomes, are therefore needed to properly deliver cancer vaccine components to skin DCs.

\section{Areas covered}

The recent insights into skin DC subsets and their functional specialization, the potential of nanoparticle-based vaccines in transcutaneous cancer vaccination and, finally, the most relevant clinical trial advances in liposomal and in cutaneous cancer vaccines will be discussed.

\section{Expert commentary}

To define the optimal conditions for mounting protective skin DC-induced anti-tumor immune responses, investigation of the cellular and molecular interplay that controls tumor progression should be pursued in parallel with clinical development. The resulting knowledge will then be translated into improved cancer vaccines that better target the most appropriate immune players.

Keywords: Cancer vaccine, liposome, nanoparticle, skin dendritic cell, transcutaneous vaccination. 


\section{Introduction}

The last decades have witnessed a gradual shift in cancer management from conventional therapy (surgery, radiation therapy, chemotherapy and endocrine therapy) to immunotherapy, mainly with monoclonal antibodies specific for tumor antigens. More recently, targeted immunotherapies, intended to break the immune tolerance induced by tumors or to actively stimulate the patient's immune system against cancer cells, have emerged. These approaches stem from our understanding that despite being antigenic and often also immunogenic, most tumors fail to induce protective immunity because of their immunosuppressive microenvironment. Immunotherapy is therefore intended to reverse this microenvironment effect, thus harnessing the immune system to attack cancer cells.

\section{Cancer immunity: challenges and vaccine design requirements}

\subsection{Protective tumor-specific immune response}

A protective adaptive immune response against tumor cells should consist of several key steps, including 1) Tumor Associated Antigen (TAA) expression by tumor cells, and release of these antigens by dying cells. 2) Release of damage associated molecular patterns (DAMPs) that provide danger signals to dendritic cells (DCs) inducing their maturation. DAMPs are recognized by specific receptors on DCs named Pattern Recognition Receptors (PRR). 3) Cross-presentation of tumor antigens by mature DCs, on MHC class I and class II molecules, to tumor-specific CD $8^{+}$ and $\mathrm{CD4}^{+} \mathrm{T}$ cells respectively. 4) Priming of tumor-specific $\mathrm{T}$ cells resulting in cytotoxic $\mathrm{T}$ lymphocyte (CTL) differentiation. 5) Migration of effector T cells and infiltration of the tumor and, finally, 6) recognition and killing of tumor cells by effector CTLs. Optimal CTL differentiation requires, in addition to mature DCs, the presence of $\mathrm{CD}^{+}$IFN- $\gamma$-producing $\mathrm{T}$ helper cells, named Th1 (figure 1). 


\subsection{Kinetics of tumor development and escape from immune response}

During the initial tumor development stage, the tumor-specific immune response is capable of eliminating all immunogenic cancer cells. Progressively, mutations decrease tumor cell immunogenicity resulting in a dynamic "equilibrium phase", where the immune system cannot destroy all cancer cells, but only most of them, to keep the cancer in a dormant state. This state will progressively fade, as specific tumor escape mechanisms, along with the exhaustion of lymphocytes, will render this immune response inefficient. At this stage, the balance between the effector and regulatory immune compartments is seriously broken and the tumor enters the "evasion phase" and develops more rapidly [1].

Tumor escape mechanisms were divided by Teng et al (2015) [2] into three major categories (table 1). First, under the selective pressure of the immune system, a myriad of genetic and epigenetic alterations occurs, resulting in several events referred to as immunoediting. They include inhibition of antigen presenting machinery, expression of new TAAs, and downregulation or loss of highly immunogenic TAAs and co-stimulatory molecules. Second, tumor cells survival and resistance to apoptosis and to cytotoxic effectors of immunity is enhanced. Third, tumors establish an immunosuppressive microenvironment by favoring the induction and recruitment of immunosuppressive cells such as regulatory T cells (Tregs) and myeloid-derived suppressor cells (MDSC). Therefore, the pattern of tumor infiltrating lymphocyte subsets is a key criterion that drives disease progression.

In addition, chronic antigen exposure causes a continuous ligation of inhibitory receptors on immune effector cells. This leads to an "exhausted" [2], characterized by Wherry et al as "a poor effector function, a sustained expression of inhibitory receptors and a transcriptional state distinct from that of functional effector or memory T cells" [3]. Under normal physiological conditions, the immunosuppressive pathways described above are crucial for the prevention of excessive immune responses and thus, the maintenance of self-tolerance by ensuring a balance between inhibitory and co-stimulatory signaling. In the case of cancer, however, these mechanisms shift the balance towards an inhibitory state [2]. 


\subsection{Therapies based on reversal of immune tolerance}

In theory, in order to reverse tumor-induced immune tolerance, the above-mentioned key steps can be targeted using two different therapeutic approaches. On one hand, administration of antagonists of inhibitory signals or agonists of co-stimulatory ones can be used to inhibit immunosuppressive mechanisms and amplify antigen-specific T cell responses. On the other hand, therapeutic cancer vaccines are intended to induce active cancer immunity either by activating pre-existing host antitumor immune cells or by inducing the differentiation of new ones.

Cancer vaccines are therapeutic preparations intended to enhance both the number and the function of tumor-specific CTLs. They should therefore contain $C D 8^{+} T$ cell epitopes derived from TAA of the targeted tumor type, as well as $\mathrm{CD}^{+} \mathrm{T}$ cell epitopes and a potent adjuvant. Mutated tumor neoantigens, which arise from point mutations that cause frameshifts resulting in new peptides, are among the most antigenic TAAs. Therefore, they are promising candidates for cancer vaccines. The adjuvant, which is usually a PRR ligand, plays the role of a danger signal that activates and drives maturation of DCs. Following uptake and epitope cross-presentation, mature DCs would induce Th cells and tumor-specific CTLs. Besides its composition, the delivery route of the vaccine is also crucial as it dictates the amount and type of DCs to be targeted. It may also contribute to vaccine-induced inflammation that plays a role in DC maturation.

The most popular vaccination routes are the intramuscular (IM) and the subcutaneous (SC) ones, mainly for their ease of administration, despite the scarcity of DCs in muscles and their virtual absence in the hypodermis. Recently, the transcutaneous approach has been considered because of the abundance of DCs in the skin. 


\section{Vaccination via the skin}

\subsection{The skin immune system}

The skin is the main barrier that protects the body from the external environment, and therefore, is continuously challenged by microbes, physical and chemical aggressions and injuries. To face these challenges, it harbors a specialized, highly complex innate and adaptive immune network, capable of mounting adequate immune responses. This 'skin immune system' (SIS) consists of specialized skin-resident immune cells, along with immunocompetent skin-trophic lymphocytes and DCs that constantly recirculate between the skin, the lymphatic vessels, the skin-draining lymph nodes and, in the case of lymphocytes, the bloodstream.

In many species, including humans and mice, the skin is anatomically composed of 3 layers, namely, from the outer to the inner side, the epidermis, the dermis and the hypodermis. The epidermis is comprised mainly of keratinocytes. Its outermost layer is the stratum corneum, or horny layer, which is composed of 4-20 layers of dead corneocytes and largely contributes the barrier function of the skin. The immune cells of the epidermis are Langerhans cells (LCS) and effector and memory $\mathrm{CD}^{+}$cytotoxic T cells. The dermis is a connective tissue composed of a fibroblast-rich network of collagen and elastin fibers embedded in proteoglycans, providing strength and elasticity to the skin [4]. It contains dermal dendritic cells (dDCs), natural killer (NK) cells, memory B and T cells as well as mast cells and macrophages $[4,5]$. The hypodermis is also called the subcutaneous (SC) tissue or adipose tissue. This layer of white fat is composed mainly of fibroblasts and adipocytes and plays a role in fat reserve and thermal isolation. Unlike the epidermis or the dermis, the hypodermis naturally lacks resident immune cells [4]. Finally, the skin contains appendages like hair follicles and sebaceous glands that together, form pilosebaceous units. Hair follicles originate from the dermis, are surrounded by an epidermal sheath [4] and are connected with a network of blood capillaries and nerve endings. The epidermal sheath surrounding the follicle is a stratified epithelium that is continuous with the epidermis. However, it is discontinued at the entrance of the sebaceous gland duct to the hair canal [6]. Thus, hair follicles represent a potential entry port for pathogens and chemicals (figure 2). 


\subsection{Skin DCs subsets}

The skin contains a large number of DCs. These immune sentinels exhibit potent phagocytic, macropinocytic and endocytic activity, thereby internalizing microorganisms, cell debris, pathogen constituents and soluble molecules from their surroundings. Their role is to constantly sample their microenvironment, process antigens and present them to $T$ lymphocytes.

\subsubsection{Langerhans cells}

LCs are the only DC subset in the epidermis, accounting for $2-5 \%$ of all epidermal cells $[4,7]$. They are characterized by a high expression of langerin (CD207) and MHC class II, an intermediate expression of $\mathrm{CD} 11 \mathrm{~b}\left(\mathrm{CD} 11 b^{\mathrm{int}}\right)$ and the absence of the integrin alpha $\mathrm{E}$ chain (CD103') [8]. Overall, 2-3 \% of LCs circulate naturally and continuously from the epidermis to the lymph nodes, across the dermis [4].

LCs are specialized in epidermal immunosurveillance. Despite their scarcity, their extensive network of dendrites covers the epidermis entirely and extends and retracts in a rhythmic manner allowing them to sample the fluid in the intercellular spaces between keratinocytes $[7,9]$. This behavior is termed "dendrite surveillance extension and retraction cycling habitude" (dSEARCH) [7]. Activated LCs can migrate to draining lymph nodes to prime antigen-specific T lymphocytes, thus initiating humoral and cellular immunity.

Additionally, upon sensing inflammatory signals, they can provide skin surface immunosurveillance by increasing their dSEARCH motion and projecting their dendrites through tight junctions between keratinocytes towards the stratum corneum [9]. Thereby, they are able to collect pathogens/particles that have not yet breached the epidermal barrier. Ouchi et al [10] have shown that after patch immunization of mice with $S$. aureus-derived toxin, a high molecular weight molecule unable to cross the stratum corneum barrier, a protective IgG1 antibody response was detectable in their sera. Similarly, confocal microscopy experiments performed on immunostained human epidermal sheets, showed that the dendrites of activated 
LCs, extend above the tight junctions [9], and internalize topically applied proteins via endocytosis.

Whether LCs are capable of immunosurveillance of the dermis is still debatable. Using a mouse model of dermal melanocytosis, Hemmi et al. suggested that epidermal LCs could not reach down to the dermis as they failed to uptake melanocyte granules [11]. However, more recently, Flacher et al. showed that monoclonal antibodies (mAb) targeting endocytic receptors were efficiently taken up by LCs in human and mouse skin explants [12]. Moreover, using in vivo experiments, they showed that these monoclonal antibodies are subsequently transported by LCs to the draining lymph nodes [13]. To explain these results, two scenarios can be proposed. It is most probable that the mAb have diffused across the basement membrane separating dermis and epidermis. Yet, it cannot be excluded that LCs have reached "down" to the dermis where they internalized them.

\subsubsection{Dermal dendritic cells}

Dermal DCs (dDCs) are heterogeneous. Their markers vary between mice and humans. In 2005, Kissenpfennig et al showed [14] that langerin/CD207, first thought to be restricted to LCs, was also expressed by some dDCs subpopulations. Based on the expression of CD207, CD11b and CD103, Henri et al [8] identified in 2010 four distinct sub-populations of DCs from digested skin: CD207 ${ }^{\text {high }}$ CD11b $b^{\text {int }}$ CD103 cells corresponds to the epidermal LCs "en route" towards lymph nodes, while the three remaining subsets are dermal resident subsets, including $C D 207^{+}$

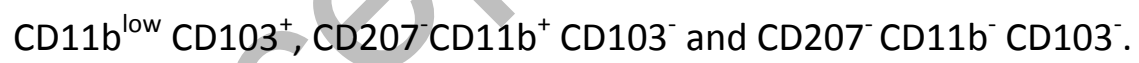

Similar to $\mathrm{LCs}, \mathrm{dDCs}$ are all $\mathrm{MHCl}{ }^{\text {high }}$. They can present antigens to $\mathrm{T}$ cells following uptake, maturation and migration to draining lymph nodes. Dermal DCs were shown to carry Leishmania major antigens [15] or locally applied ovalbumin antigens [16] to draining lymph nodes, where they induced antigen-specific T cell proliferation. 


\subsection{Antigen presentation potential of skin DCs}

\subsubsection{Endocytic receptors of skin DCs}

Skin DCs are equipped with a panel of receptors that mediate pathogen/vaccine uptake and tailor vaccine-induced immune responses [17]. Among these, endocytic receptors of the C-type lectin superfamily recognize pathogen-specific carbohydrate structures. They therefore offer the opportunity of targeting the endocytic pathway via their specific ligands. Examples of endocytic receptors are DC-SIGN/CD209, Langerin/CD207, Clec9A/DNGR and the mannose receptors family, including the mannose receptor MR/CD206, DEC-205/CD205, Endo180, and the M-type phospholipase A2 receptor [18].

3.3.2.Skin DC function in cellular immune response activation: relevance to cancer vaccination?

Protective immunity against cancer cells requires cross-presentation of exogenous antigenic peptides on both $\mathrm{MHC}$ class I and class II to $\mathrm{CD}^{+}$and $\mathrm{CD}^{+} \mathrm{T}$ cells respectively, in order to drive CTL differentiation. While it is established that under inflammatory conditions, both LCs and $\mathrm{dDCs}$ have the ability to induce a specific immune response against foreign pathogens, their selective capacity in initiating and driving cancer-specific immune response is largely debated (Table 2).

Early studies suggested that only LCs were capable of cross-presentation. LCs differentiated in vitro from human $\mathrm{CD} 34^{+}$hematopoietic progenitors were shown to sample necrotic/apoptotic melanoma cells and efficiently prime $\mathrm{CD} 8^{+} \mathrm{T}$ cells thereby generating melanoma-specific CTLs [19]. In another study, LCs that were induced to migrate from the epidermis in the presence of external stimuli had the ability to cross-present both soluble and cell-bound protein antigens on their MHC class I molecules and to induce CTLs capable of killing antigen-loaded cells $[12,20]$. In 
vivo, it was reported that both intradermal and transcutaneous immunization resulted in $\mathrm{CD} 8^{+} \mathrm{T}$ cell proliferation in draining lymph nodes $[20,21]$.

On the other hand, LCs are believed to play an immunoregulatory role to promote tolerance and prevent excessive inflammation. For example, they were shown to constitutively promote local proliferation and activation of skin resident memory $\mathrm{CD} 4^{+}$regulatory $\mathrm{T}$ cells (Treg) and to migrate to skin-draining lymph nodes where they present self-antigens to $T$ cells $[22,23]$. Moreover, the depletion of LCs in a mouse model of contact hypersensitivity resulted in a higher number of antigen-specific effector T cells, without affecting the Treg count [24].

Regarding dDCs, recent reports suggested that langerin ${ }^{+} \mathrm{CD}_{103^{+}} \mathrm{dDCs}$ are particularly potent in terms of cross-presenting antigens to $\mathrm{CD} 8^{+} \mathrm{T}$ cells [8,25]. Other $\mathrm{dDC}$ subpopulations, on the other hand, fail to cross-present endogenous and viral antigens $[8,25]$ and seem to mediate mostly $\mathrm{CD}^{+} \mathrm{T}$ cell priming [25]. It should be noted, however, that cross-presenting langerin ${ }^{+}$ $\mathrm{CD}_{103}{ }^{+} \mathrm{dDCs}$ represent a very small population (2.6\%) of dDCs [26].

Another level of complexity was revealed when it was found that targeting a given C-type lectin receptor does not invariably generate the same type of immune response in different DCs; similarly, within the same DC population, signaling via different C-type lectin receptors may lead to different outcomes. For example, early works suggested that targeting either DEC205/CD205 or langerin/CD207 results in efficient cross-presentation and proliferation of CD4 ${ }^{+}$ and $\mathrm{CD}^{+} \mathrm{T}$ cells [21]. However, newer results indicated that these two receptors might not be similarly involved in antigen presentation, depending on the DC subset that captures the targeting antibody. Indeed, LCs targeted through DEC-205/CD205 seem to perform crosspresentation and promote $\mathrm{CD}^{+} \mathrm{T}$ cell proliferation [12,27], while those targeted through langerin rather tolerize $\mathrm{CD}^{+} \mathrm{T}$ cells for the antigen $[12,26]$. Conversely, antigen capture by langerin ${ }^{+} \mathrm{CD}_{103}{ }^{+} \mathrm{dDC}$ s via either langerin of DEC-205 consistently leads to potent CD8+ T-cell responses $[12,26]$. Further exploration of methods allowing selective targeting and stimulation of LCs and dDCs is needed to achieve the most appropriate cross-presentation of vaccine antigens. 
Altogether, the current findings of skin immunobiology have so far proven the undeniable skin potential of mounting immune responses. The various, often controversial reports underline the skin DCs ability in driving the immune response either toward an immunostimulatory or an immunoregulatory state, depending on specific conditions (type and dose of antigen, danger signals, targeting receptor). This highlights not only the flexibility of the skin-induced immune responses, but also the high specialization and cooperation between different skin DC subsets. Further understanding of their activation conditions and their respective contribution in T cell priming and CTL induction is still needed for the development of improved skin-delivered vaccines.

\section{Strategies of transcutaneous vaccination}

\subsection{Transcutaneous vaccination: making skin DCs the main vaccine recipients}

Cutaneous vaccine delivery routes are distinguished as subcutaneous when the injection targets the hypodermis, intradermal when the vaccine is delivered within the dermis and transcutaneous (TC) when it is applied on the epidermis. Although subcutaneous injections are widely used with acceptable results, this route ensures only suboptimal delivery of vaccines since the hypodermis is naturally devoid of skin-resident DCs (LCs and dDCs). Therefore, direct delivery of antigen to these cells appears as a potentially more efficient, alternative for cancer vaccination. Since intradermal vaccination does not favour uptake by LCs, the TC route is worth investigating. However, despite its promising potential, it is hampered by the stratum corneum, the impermeable outermost skin layer. The ultimate goal of TC vaccination is to ensure noninvasive antigen delivery through this barrier to the targeted DCs in the internal skin layers.

\subsection{Barrier role of the stratum corneum}

The stratum corneum exhibits highly selective permeability dictated by the size and lipophilicity of applied molecules. Depending on these parameters, TC passage of the vaccine molecules implies their uptake through multiple ports of entry that can be, either transepidermal, comprising the intercellular and the transcellular routes, or transfollicular (Figure 3 (a)). 
For the transepidermal passage, only molecules smaller than 500 Daltons have a chance to cross the stratum corneum and reach internal skin layers [28]. The intercellular way is the most predominant route for transepidermal passage, especially for small uncharged, relatively lipophilic, molecules. However, small highly hydrophilic molecules and specific peptides, known as cell-penetrating peptides, were reported to cross the epidermis via the intracellular route [29-32].

The stratum corneum is composed of keratin-rich dead corneocytes embedded in a lipid matrix [33]. In normal conditions, the fluid fraction is minimal and both lipids and keratin are solid, resulting in skin impermeability and elasticity. An increase in the fluid fraction can yield to mild transient permeabilization of the stratum corneum towards polar and apolar compounds. Achieving a hydration gradient can be performed by increasing the proportion of natural skin moisturizing factors (e.g. urea, glycerol) [34], by skin hydration prior to immunization or by applying occlusive bandage after vaccination. Once internalized, vaccine molecules diffuse toward the higher hydration gradient presented by the circulation under the epidermis.

The transfollicular route contributes largely and in different ways to TC crossing. The epithelium of the hair follicle infundibulum is immature, permitting the passage of soluble antigens [35] and selective entry of small particles [36]. Hair follicles have a reservoir function, however, they occupy less than $0.1 \%$ of the total skin surface, and their density varies considerably according to body sites and individuals [35]. Besides, all hair follicles are not available for particles penetration: only "active" hair follicles are "open" for transfollicular passage, as hair growth and/or sebum production ensure removal of plugs formed by shed corneocytes and excess sebum [6].

\subsection{Physical barrier disruption}

The physical properties of classical vaccines are usually not adapted for the TC route. In recent years, several barrier-disrupting and permeation-enhancing strategies have been developed, in addition to innovative vaccine formulations. Two types of strategies are currently used for 
stratum corneum barrier disruption: the first one relies on removal of one or more layers prior to vaccine application and the second relies on driving the vaccine components through the stratum corneum (Table 3).

Sandpapering, skin waxing and skin surface stripping are widely used to remove hair, excess sebum and a few layers of the stratum corneum [38,39] (Figure 3 (b)). Skin surface stripping was tested in preclinical trials and in humans to promote antigen penetration through the transepidermal or the transfollicular route. The technique resulted in an improvement in the immunogenicity of applied vaccines $[4,37,47]$, but was uncomfortable to the patient. An alternative cyanoacrylate skin surface stripping procedure on human skin [48] proved to be more efficient and less uncomfortable.

Techniques using an external driving force include sonoporation, electroporation and thermal poration to transiently and locally disrupt the stratum corneum, or the use of jet injectors and micro-/nano-needles to deposit the vaccine directly inside the live skin layers (Figure 3 (b)). Recent reports on preclinical trials of cancer transcutaneous vaccination using microneedles have shown promising results. For instance, in mice, two microneedle-delivered cancer vaccines were capable to induce humoral and cytotoxic responses and to slow tumor growth upon challenge. The first is a DNA vaccine for cervical cancer [49], while the second is a microparticulate vaccine based on a whole cell lysate of a murine ovarian cancer cell line [50].

\subsection{Innovative vaccine formulations for skin barrier crossing}

To enable TC antigen delivery, another attractive strategy relies on the vaccine formulation itself.

\subsubsection{Peptide-based vaccines combined to adjuvants}

The current trend with vaccine design is to replace whole microorganism-based vaccines that are often toxic and reactogenic with proteins or even small synthetic peptides. Given their small 
size, these vaccines offer the additional advantage of being more suitable for the TC route. However, unlike whole microorganism-based vaccines, they are devoid of Microbe Associated Molecular Patterns (MAMPs) that provide danger signals to PRRs. Therefore, they are poorly immunogenic and require the co-administation of adjuvants to provide these signals and induce DC maturation. Classical adjuvants come in the form of emulsions (such as MF59 and Incomplete Freund's adjuvant, termed montanide when it is clinical grade) or colloids (such aluminum hydroxide called alum and aluminum phosphate). When they are injected, this physical form of results in a depot effect that ensures slow release of the vaccine components at the administration site, thereby increasing their uptake and presentation to DCs. Moreover, Alum induce danger signal by targeting the NALP3 PRR [51]. However, emulsions and colloids are not suitable for TC administration since they are unable to cross the cutaneous barrier [51]. Alternative modern adjuvants are pathogen-derived components, chosen to function as MAMPs, like lipopeptides, recombinant proteins and nucleic acid sequences.

\subsubsection{Nanoparticles for transcutaneous immunization}

Nanoparticles are well known for their capacity to permeate the skin and mediate delivery of compounds of different sizes and polarities, therefore, their use has become a popular strategy for TC vaccine delivery. Nanoparticles can effectively co-deliver the needed adjuvant along with the vaccine antigen(s), and they improve the stability of the vaccine by protecting it from the external environment and ensure its controlled slow release at the delivery site. Moreover, their formulation techniques are flexible allowing addition of the needed adjuvant and of various "ligand" molecules on their surface for targeted delivery. Their size and zeta potential can be modified for optimal transdermal passage, uptake by DCs and subsequent immune response.

"Nanoparticles" (NP) designate matricial as well as vesicular colloidal systems. Matricial systems are nanospheres made of a matrix of polymers or of solid lipid(s), where the active compounds are interspersed. Immunostimulating Complexes (ISCOMs) are one of the most successful examples. These are spherical cage-like particles, approximately $30-40 \mathrm{~nm}$ in diameter, made of cholesterol, phospholipids and glycosides (Quill A saponins), with a potent adjuvant property. Vesicular systems can also be made of polymers or lipids (the bi-layered lipid vesicles liposomes 
for example) but they have an inner liquid (aqueous or lipid) core. Active components can be incorporated either in their core or in the surrounding layer(s), or they can be attached or adsorbed on their surface (figure 4).

\subsubsection{Physicochemical properties influencing nanoparticles interaction with the skin} immune system

Size. Nanoparticle size is a critical parameter that does not only largely predict TC passage, but also uptake by DCs and lymphatic draining efficiency. It was reported that the upper limit for intact skin absorption was $20 \mathrm{~nm}$, while barrier-disrupted skin allows passage of nanoparticles up to $50 \mathrm{~nm}$ in diameter [52,53] and even $200 \mathrm{~nm}$ for ultradeformable ones [54]. Interestingly, the optimal particle size for transfollicullar passage was reported to be in the $600 \mathrm{~nm}$ range, allowing the highest penetration depth [55] (figure 5).

Nanoparticles ranging from 40 to $200 \mathrm{~nm}$ are optimal for fast and efficient uptake by DCs [56,57], including LCs [58]. Such virus-sized particles enter cells either by receptor-mediated endocytosis into clathrin-coated pits $(<150 \mathrm{~nm})$, or through caveolae $(50-80 \mathrm{~nm})$. Particles 500$5000 \mathrm{~nm}$, considered to be bacteria-like in size, are preferentially taken up by macrophages instead of DCs, through phagocytosis [56] (figure 5).

Nanoparticles were shown to enhance the efficacy of anticancer vaccines by ensuring targeted delivery of tumor antigen and adjuvant to lymph node-resident antigen presenting cells, following intradermal injection [59]. Nanoparticles ranging from 10 to $100 \mathrm{~nm}$ seem to be most optimal for lymphatic draining. They can efficiently drain to regional lymph nodes while being sufficiently retained in the vaccination site, thereby increasing the chance of antigen uptake and presentation by DCs [60]. Within this range, particles of $20 \mathrm{~nm}$ and $45 \mathrm{~nm}$ diameter seem to be the most efficient for lymphatic draining [61]. Indeed, particles of $100 \mathrm{~nm}$ diameter were found to be 10 times less efficient of those of $25 \mathrm{~nm}$ diameter in lymphatic transport and accumulation in lymph nodes [62]. Large particles ( $>500 \mathrm{~nm}$ diameter) are very poorly drained to lymph nodes, whereas small ones $(<10 \mathrm{~nm})$ diffuse so rapidly that their chance to encounter DCs is minimized [60] (figure 5). 
An in vivo study conducted by Fifis et al showed that among intradermally injected polystyrene nanoparticles ranging from $20 \mathrm{~nm}$ to $2000 \mathrm{~nm}$, optimal immunogenicity was achieved by those in the viral size range of $40-50 \mathrm{~nm}$ [63]. A closer assessment of the influence of minute differences in nanoparticle size showed that intradermal administration of $40-49 \mathrm{~nm}$ nanobeads activates IFN- $\gamma$ secreting $C D 8^{+} T$ cells, while that of $93-123 \mathrm{~nm}$ ones induces a CD4 ${ }^{+} \mathrm{T}$ cell response and IL-4 [64] (figure 5). These findings underline the influence of the particle size on the cytokine profile and the type of elicited immune response, which may be of particular importance in the case of transcutaneous vaccination against cancer that requires $C D 8^{+} T$ cell activation and IFN- $\gamma$ secretion.

Charge. The nanoparticle surface charge, reflected by its zeta potential, can largely affect its capacity to penetrate the skin. As the skin is negatively charged, it is expected to be more efficiently crossed by cationic or neutral nanoparticles. Indeed, such nanoparticles, like liposomes, were found to be more efficient in drug delivery into deep skin layers [65]. However, Kohli et al reported that only negatively charged latex particles could permeate through the skin. This unexpected finding was attributed to their passage via channels created by the repulsive forces between them and negatively charged skin lipids [52].

When it comes to internalization into DCs, it was demonstrated that charge is only important for larger particles: $1 \mu \mathrm{m}$ polystyrene particles were more efficiently taken up when positively charged, while for those $<500 \mathrm{~nm}$, the degree of internalization is independent of the surface charge $[57,66]$.

How surface charge affects the induced immune response is still debatable. Nakanishi et al reported that protein antigens encapsulated into cationic liposomes are best delivered to APC cytosol and loaded on MHC class I, thus eliciting a cellular immune response [67]. Alternatively, Cui and Mumper showed that anionic chitosan-based nanoparticles induce higher antibody titers and cytokine production than cationic ones [68].

It is undeniable that these basic intrinsic properties can influence to a large extent nanoparticle penetration into the skin, their uptake by DCs and their immune activation properties. 
Nevertheless, current available data does not make it yet reasonable to draw final conclusions. Additionally, initial nanoparticle properties may not be sufficient to predict their behavior in vivo since they may be altered by their interaction with the skin lipids or with physiological fluids: nanoparticles can possibly aggregate to the micron-scale, their charge may change, etc.

Smart nanoparticle systems. These nanoparticles are designed to be applied through the transfollicular route and to release their active components only upon specific stimuli in order to increase follicular penetration of vaccine molecules. For example, bovine serum albumin nanoparticles encapsulating active compounds can be applied simultaneously with protease. Their subsequent enzymatic degradation ensures protease-triggered controlled release of their content [69].

\subsubsection{Potential of liposomes for transcutaneous immunization}

Liposomes were the first nanoparticles to be developed, about 40 years ago, and they remain the most investigated ones. They are the subject of a high number of patents and are available on the market as vectors of vaccines [70-72] and transcutaneously delivered drugs $[73,74]$. These are nanometric vesicles, composed of natural or synthetic biodegradable, cholesterol containing, phospholipid bilayers surrounding an aqueous core. Their zeta potential is defined by the nature of their phospholipids. Their structure allows them to transport both hydrophilic substances encapsulated in their core, and hydrophobic ones integrated in their lipid bilayers. Because their composition is closely related to that of biological membranes, they are highly tolerable and bear low intrinsic pro-inflammatory activity and are therefore among the most attractive nanoparticles for vaccination [75]. Liposomes provide passive targeting of skin DCs. Indeed, they are rapidly internalized by surrounding cells, ensuring a sufficient amount of vaccine is collected by the DCs, while "non-packaged" vaccines are less stable and risk rapid draining of their components.

Efficacy of liposomal carriers in TC crossing has been established since 1980, when they were used for the first time for topical drug delivery [76]. In this study, they were shown to achieve a four- to five-fold increase of the drug concentration in the epidermis and the dermis, as 
compared to drug alone. Subsequent studies have however proposed their relatively rigid structure to be suboptimal for skin penetration. Liposomes were thus proposed to enhance drug deposition only in the upper layers of the stratum corneum, without reaching the internal living layers [77]. Because of their unique versatility in composition and size, liposomes are actively investigated as vehicles for TC vaccination. To increase skin penetration, many variants have been developed including transfersomes and ethosomes.

The term "transfersomes" was introduced for the first time by Cevc and Blume in 1992 [78] and is a trademark of IDEA AG, Munich, Germany. They are ultradeformable liposomes made with small unsaturated soybean lecithin and an edge activator, usually a surfactant. They are able to squeeze into pores much smaller than their size and to carry a remarkable amount of lipid into the skin. Therefore, they were expected to enhance cutaneous vaccine delivery through the stratum corneum with minimal barrier disruption [79]. For instance, Wang et al. found that cationic ultradeformable liposomes delivering $\mathrm{HBs}$ antigen DNA by the TC route induce potent cellular and humoral immune responses that were superior to those induced by conventional liposomes, and comparable to intramuscular injection of naked DNA [80]. Additionally, Gupta et al found that transfersomes induce higher anti-TT titers as compared to conventional liposomes [81]. Similarly, transdermal immunization with ultradeformable liposomes was reported to induce stronger cellular and humoral immunity against merozoite surface protein-1 (PfMSP119) of Plasmodium falciparum, as compared to conventional liposomes [82]. However, contradictory results about the transfersome's increased potential as compared to conventional liposomes can also be found $[32,83]$.

Ethosomes are obtained by adding a high percentage of ethanol (up to $45 \%$ ) to conventional liposomes, thus significantly increasing their fluidity [83]. Rattanpack et al reported them to be the most efficient vesicular carriers. It is also possible to combine ethanol and surfactants in a single nanoparticle to maximize the fluidity enhancement effect. The resulting vesicles are called transethosomes $[54,84]$.

\subsubsection{Adapting nanoparticles for adequate skin DC targeting}


In order to benefit from the skin potential in mounting protective immune responses following TC vaccination with nanoparticles, these particles should be able to reach, target and activate the most appropriate skin DCs (epidermal LCs and/or dDCs) that would induce Th1 and CTL responses. Targeting nanoparticles to receptors expressed on skin DCs improves the interaction between them. Espuelas et al. showed that adding a mannose residue to liposomes enhanced their uptake by human DCs through mannose receptor-mediated endocytosis [85]. When mannosylated liposomal cancer vaccines were injected SC in tumor-bearing mice, it was possible to decrease the adjuvant dose up to 100 -fold without any loss in the anti-tumoral efficiency [86]. Translation of this strategy would be particularly interesting in TC vaccination where the minimal amount of vaccine that crosses the stratum corneum barrier would be compensated by a higher uptake by skin DCs.

\section{Transcutaneous cancer vaccination using nanoparticles: where do we stand?}

To date, the search by keywords "cancer vaccine" yields to more than 1800 returns in the National Institute of Health database for clinical trials (www.clinicaltrials.gov). Out of these, 185 studies (10\%) are in phase 3 and only two therapeutic cancer vaccines, Sipuleucel-T (Provenge ${ }^{\circledR}$ ) [87] and talimogene laherparepvec (IMLYGIC, Amgen, Inc.) [88], have been licensed for clinical use. These numbers underline not only the great efforts that are being dedicated to cancer vaccine research, but also the challenges faced in the development of such vaccines. Despite their extensive diversity (purified peptides, proteins, antigen-loaded autologous DCs, nanoparticle-based vaccines, etc), all of these vaccines are required to elicit specific CD4+ cells and protective CTL responses. In addition, some were designed to also induce humoral responses. Various administration routes have been applied in clinical trials. While most vaccines are delivered subcutaneously [89-96] a few are delivered intradermally [97-99]. A combination of both routes has also been tested and is known as intracutaneous $[100,101]$. However, cancer TC vaccination in humans has rarely been tested [102] and never with nanoparticle-based vaccines (Tables 4 and 5 ).

\subsection{Nanoparticle-based cancer vaccines in development}


Various nanoparticles like nanoemulsions, polymeric and magnetite nanoparticles, ISCOMs and liposomes have shown efficacy in vaccine preclinical trials, but only the ISCOMs and liposomes have reached clinical studies.

\subsubsection{ISCOM-based cancer vaccines}

ISCOMs were first used to deliver viral and bacterial antigens. The promising results prompted the development of ISCOM-based antitumoral vaccines. The cage-like matrix of ISCOM nanoparticles is designated as ISCOMATRIX. An ISCOM-based cancer vaccine specific for NYESO-1 has been tested in clinical trials. NY-ESO-1 is a cancer-testis antigen expressed in normal testis but also in tumors of various tissues, including melanoma and ovarian cancer. In a phase I clinical trial involving patients with resected melanoma, it elicited NY-ESO-1-specific antibody responses, $\mathrm{CD}^{+}$and $\mathrm{CD}^{+} \mathrm{T}$ cells [92] and persistent memory [94]. In a phase II clinical trial conducted on advanced metastatic melanoma patients, antibody responses were confirmed, however patients

failed to develop cellular immunity and had no clinical benefits [95]. In an attempt to increase the NY-ESO-1 specific $\mathrm{CD}^{+} \mathrm{T}$ cell response, this vaccine was combined to a recombinant NYESO-1 fowlpox virus in a heterologous prime-boost strategy. In a phase I clinical trial, it gave positive $\mathrm{CD}^{+} \mathrm{T}$ cell responses in $3 / 18$ patients [96].

\subsubsection{Liposome-based cancer vaccines}

Cancer liposomal vaccines have been extensively used in preclinical studies where they have shown variable efficacy. A vaccine was developed against hepatocellular carcinoma. It bears a peptide derived from Glypican-3 (GPC3), a TAA overexpressed in this type of cancer. Although devoid of an adjuvant molecule, this vaccine resulted in an inhibition of tumor growth [103]. Another vaccine expressing murine ErbB2-derived peptide and incorporating the TLR4 ligand Monophosphoryl lipid A (MPLA) was evaluated in mice. Subcutaneous injection of this vaccine resulted in the induction of a CTL response, yet, showed only partial protection against ErbB2expressing tumors [104]. We have designed a peptide-anchoring liposome-based vaccine expressing a human ErbB2-derived $\mathrm{CD}^{+} \mathrm{T}$ cell epitope, a universal $\mathrm{CD} 4^{+} \mathrm{T}$ cell epitope and, dipalmitoyil alanyl cysteine glycine (Pam $\left.{ }_{2} \mathrm{CAG}\right)$, a potent TLR2/6 ligand. This vaccine was 
evaluated in a mouse model bearing transgenic murine renal carcinoma cells expressing the human ErbB2 protein. It induced a specific immune response against the ErbB2 peptide and exhibited an efficient antitumoral effect after subcutaneous injection [86] and needle-free airway administration $[105,106]$.

One of the most promising liposome-based formulations that proved to be efficient in preclinical trials was developed by Immunovaccine (Halifax, Canada) under the name of VacciMax ${ }^{\circledR}$. This vaccine-enhancement platform consists of a water-in-oil emulsion in which liposomes are emulsified in Incomplete Freund's adjuvant. A more stable, water-free, generation of VacciMax, called Depovax ${ }^{\circledR}$ (DPX) was developed for clinical trials. It consists of lyophilized liposomes re-suspended in montanide immediately prior to vaccination [107]. DPX0907, one of the variants of Depovax ${ }^{\circledR}$, contains a TLR ligand, a universal Th peptide derived from tetanus toxoid, as well as seven human leukocyte antigen (HLA)-A2 restricted peptides derived from various TAAs. These peptides are specifically presented by MHC class I on breast, ovarian, and prostate cancer cells [89]. A phase I clinical trial of DPX-0907 increased the frequency of $\mathrm{CD}^{+} \mathrm{T}$ cells in advanced-stage breast, ovarian and prostate cancer patients, with $61 \%$ immunological response rate and induced antigen-specific $T$ cell memory [90]. This clinical trial provides a rationale for further evaluation of the clinical benefits of DPX-0907, especially in breast and ovarian cancer subjects. It is to be noted however, that the integrity of the liposomes when suspended in a mineral oil such as montanide may have been affected and the clinical benefit of this formulation cannot therefore be attributed with certainty to the liposome formulation or to the adjuvant itself.

BLP25 or tecemotide, also known as Stimuvax ${ }^{\circledR}$, is another promising liposomal anti-cancer vaccine that has reached late clinical stages. It consists of a multilamellar liposome incorporating a TLR4 ligand (MPLA), and BP25, a peptide derived of the mucin 1 (MUC1) protein. MUC1 is a TAA overexpressed in more than $90 \%$ of adenocarcinomas including breast and lung cancers. BP25 contains $\mathrm{CD} 4^{+}$and $\mathrm{CD} 8^{+} \mathrm{T}$ cell epitopes. Phase I and II trials conducted on non-small-cell lung cancer patients showed tolerability, induction of MUC1-specific T-cell proliferation and cytokine production as well as extended median survival [91]. However, in a 
randomized phase III trial designated START (Stimulating Targeted Antigenic Responses to NSCLC), BLP25 alone did not provide any significant survival benefit. Nonetheless, it was shown to be beneficial for patients treated with concurrent chemotherapy by providing a 10.2 months extension of overall survival [108]. An additional 20 months median follow-up time confirmed these findings [93].

\subsection{Transcutaneous cancer vaccines in clinical trials}

In the vast majority of cancer vaccine trials involving the cutaneous route, antigen administration is performed either subcutaneously or intradermally, while the adjuvant is applied topically. The goal of this strategy is to deliver sufficient amounts of the antigen in the dermis and simultaneously activate LCs in the epidermis by the adjuvant.

This combination protocol was first used for a melanoma vaccine based on full length NY-ESO-1 protein. In a phase I clinical trial where non emulsified NY-ESO-1 was injected ID, and imiquimod, a TLR7 agonist was applied TC, a specific humoral response was elicited, however, this vaccine failed to induce a $\mathrm{CD} 8^{+} \mathrm{T}$ cell response [99]. An improved vaccine in which NY-ESO-1 protein was emulsified in montanide and imiquimod was replaced with resiquimod, a related more potent TLR7/8 agonist, resulted in a potent humoral immune response and a $\mathrm{CD} 8^{+} \mathrm{T}$ cell response was induced in 3/12 patients [98].

CDX-1401, another NY-ESO-1 based vaccine, is composed of the full length NY-ESO-1 protein fused to a human mAb targeting the DEC-205 receptor expressed on DCs. It was tested in a phase I clinical trial in 45 patients with diverse advanced malignancies, in combination with various TLR ligands (Resiquimod targeting TLR7/8 and poly-ICLC targeting TLR 3), both by the SC and the TC routes. Persistent cellular immunity and clinical benefits were observed in $56 \%$ and $29 \%$ of the patients respectively, distributed to all study cohorts, independently of the administration route [101].

As of today, only one clinical trial was conducted on a cancer vaccine administered exclusively through the TC route. This vaccine consisted of a mixture of melanoma-derived peptides dissolved in DMSO (Dimethylsulfoxide). Melanoma patients were vaccinated TC after skin 
barrier disruption by tape stripping. The vaccine provided an overall survival of 55.8 months for patients who responded to all vaccine peptides, compared to 20.3 months for partial responders [102].

These studies provide evidence of the efficiency of skin DCs in inducing tumor-specific CD $8^{+} \mathrm{T}$ cell responses when they are activated under the appropriate conditions and an additional rationale for the use of the TC route for cancer vaccination. Future studies will likely explore more closely the exact factors that drive optimal immune responses against topically applied vaccines and uncover more potent adjuvant molecules that can better amplify tumor-specific CTL responses. 


\section{Conclusion}

The key to successful cancer immunization resides in appropriate activation of DCs capable of reversing the tumor-induced immune tolerance. The skin has a unique and potent immune network, especially rich with DCs capable of inducing and tailoring immune responses. Skin DCs have shown a potential for driving tumor-specific immune responses in mouse models and in humans. Needle-free, nanoparticle-mediated, transcutaneous delivery of cancer vaccines is therefore intended to target skin DCs including LCs and dDCs, in order to improve tumorspecific immune response amplitude and quality. Several strategies acting on the level of the vaccine formulation (carrier, adjuvant, DC targeting molecules ...) and on the TC vaccination techniques (tape stripping, microneedles ...) have been developed to overcome the stratum corneum barrier. A careful combination of these strategies is expected to drive the development of next generation cancer vaccines.

\section{Expert commentary}

Cancer vaccination is far more challenging than microbial vaccination. While microbes express a large panel of MAMPs and antigens that are strong activators of innate and adaptive immunity, cancer cells express mostly self-antigens. TAAs are generally poorly immunogenic. Additionally, within a single tumor, cancer cells may have different TAA expression profiles and exhibit different escape mechanisms. Consequently, despite decades of efforts, cancer vaccination has not yet reached its golden age. The major challenge is therefore to induce a protective immune response against carefully selected TAA peptides properly presented by adequate DCs. Only two cancer vaccines are currently in clinical use.

On the other hand, recent efforts have focused on harnessing the antigen presentation potential of skin DCs. Several strategies have been developed to overcome the barrier of the stratum corneum, including the use of nanoparticles. Encouraging results reported in clinical 
trials of intradermal administration of a virosomal influenza vaccine are good proof of the feasibility of this approach.

Unfortunately, our knowledge of skin immunobiology is still incomplete. A large number of studies have been conducted, but their experimental settings varied extensively, thereby leading to contradictory results. For instance, the respective roles of $L C S$ and $d D C$ subpopulations in immune activation are far from being elucidated: the first studies suggested that LCs were the only players in antigen cross-presentation, but later, it was found that CD207/Lang ${ }^{+}$dDC are also involved. Therefore, this role remains to be attributed to one or the other or both populations.

Our knowledge about the ideal nanoparticles properties for TC vaccination is also limited. We need better investigation of the influence of nanoparticles physicochemical characteristics (size, charge, and composition) on skin barrier crossing, targeting and activation of adequate antigen presenting cells. Reported studies have used a large variety of models: nanoparticles were tested either in vivo or on human or porcine skin explants that may be frozen/thawed or fresh. These tests lead obviously to non-coherent, often contradictive results.

The high number of variables should therefore be counterbalanced by the establishment of common study design or, better, by organizing the laboratories into consortia. Centralization of generated data is expected to elucidate the networks of cellular cooperation that arise between these cells and identify optimal nanoparticle properties for specific targeting of the desired DC subpopulation.

Another challenge resides in the choice of molecules to be incorporated in the nanoparticles. Indeed, single epitope vaccination approaches are MHC dependent and would be effective only in a subpopulation of cancer patients expressing the appropriate HLA genotype. Therefore, multi-epitope vaccines might be more adequate. Moreover, when the selected epitopes are derived from multiple TAAs, they decrease the risk of emergence of vaccine resistance following TAA dowregulation by tumor cells. This argues for the need for additional profiling of different malignancies, in order to identify the most relevant TAA peptides in each cancer type. 
Further studies are also needed to identify optimal targeting and adjuvant molecules to improve uptake and activation of DCs.

Finally, there is a need to improve the reproducibility of transcutaneous vaccination techniques. Current practices may lead to variable results between individuals depending on the zone, size and hair follicle density of the application site. Development of transcutaneous vaccination devices that help standardizing the process deserves further attention.

For all these reasons, it will be many years before transcutaneous cancer vaccination unleashes its full potential. The half way target that currently seems the most reachable is the local treatment of melanomas, because lymphocytes primed by skin-derived DCs express skin homing receptors and are sufficiently recruited to the vaccination site. Additionally, combinatorial therapeutics, whether exclusively immunological, such as TC cancer vaccines and immune checkpoint inhibitors, or mixed immunological-chemical, such as TC cancer vaccines with concomitant chemotherapy, seem to be equally promising on the short-term.

\section{Five-year view}

This review of cancer vaccination strategies that are currently being investigated highlights the exponential growth of our understanding in the recent years. Important discoveries have been made in different converging fields, including tumor biology (TAA expression, escape mechanisms), cancer specific immunity (immune checkpoints, antigen presentation), vaccinology (adjuvantation, nanoparticles and cell targeting) as well as skin immune potential $(L C, d D C)$. They are expected to progressively bridge the gap in knowledge regarding optimal TC cancer vaccine formulations and skin DC targeting strategies. As the respective roles of skin DC subpopulations will be better understood, appropriate ways of targeting them through nanoparticles and targeting molecules will be optimized. Identification of new adjuvants adapted to TC delivery will further improve vaccine efficacy.

Many clinical trials are already in the pipeline, with the most advanced being for melanoma treatment. Obviously, in the case of melanoma, topical application of the vaccine directly on 
the cancer lesion is expected to induce local protective immunity, but this is not the only intended effect. Indeed, similar to the currently used intratumoral melanoma vaccine (T-VEC), TC melanoma vaccines are expected to induce also systemic immunity, leading to the regression of metastatic lesions distant from the vaccination site. If such findings are confirmed, they will strongly encourage the application of TC vaccination to other kinds of tumors.

Finally, it will be interesting to evaluate in clinical trials the addition of TC vaccines to currently validated therapies based on immune checkpoint modulators and/chemotherapeutic drugs. Their purpose would be to tip the balance from immune tolerance of tumors toward tumor rejection.

\section{Key issues}

- Cancers escape the immune system through many mechanisms, including immunoediting. Despite the potential immunogenicity of tumor cells, protective immune responses are rarely elicited and the balance is tipped towards tumor tolerance, thus favoring cancer aggressiveness and progression.

- To restore efficient immune rejection, cancer vaccines must re-educate the immune system to overcome tumor-induced tolerance.

- The skin harbors a complex network of dendritic cells. Langerhans cells and $\mathrm{CD}^{207^{+}} /$Langerin $^{+}$dermal dendritic cells are thought to be potent inducers of $\mathrm{CTL}$ responses which are crucial for tumor specific immunity. Targeting these dendritic cells is possible through the transcutaneous route, if the vaccine can cross the impermeable stratum corneum barrier.

- Several strategies were recently developed to allow vaccine formulations to overcome the stratum corneum barrier. They include the incorporation of vaccine components into nanoparticles and the disruption of the skin barrier by microneedles and other means.

- Research is currently focusing on determining critical nanoparticle properties, such as size, charge and composition, for optimal delivery to skin dendritic cells and uptake. 
Because of their versatility and their similarity with biological membranes, liposomes are among the most promising nanoparticles adapted for transcutaneous immunization.

- In liposome-based vaccines, antigenic molecules can be incorporated into the liposome or expressed on its surface. Adapted adjuvants that are suitable for skin barrier crossing can be added. Additionally, it is possible to insert, in the liposome surface, DC targeting molecules whose receptors are differentially expressed on skin DC subsets. This strategy allows the delivery of a greater vaccine cargo to the desired cells. Sometimes, these receptors can also have an immunostimulatory role.

- Recently, several clinical trials have translated preclinical findings into human testing. Liposome-based vaccines are under current clinical investigation by classical routes. On the other hand, peptide-based vaccines are being investigated by the TC route. A combination of the key elements of these success stories is expected to drive TC cancer vaccination using liposomal peptide vaccines into clinical development. 


\section{Funding}

Funding from the following academic agencies: Alsace contre le Cancer, CEDRE program, Centre National pour la Recherche Scientifique, Ligue contre le Cancer,Lebanese University, University of Strasbourg.

\section{Declaration of interest}

H Saliba received PhD grants from CEDRE program, Centre National pour la Recherche Scientifique in Lebanon, Ligue contre le Cancer and University of Strasbourg. S Chamat received research grants from CEDRE program and the Lebanese University. B Heurtault has received research grants from Centre National pour la Recherche Scientifique in France, Ligue contre le Cancer and University of Strasbourg and Alsace contre le cancer. H Bouharoun-Tayoun has received a research grant from the Lebanese University. V Flacher has received research grants from Ligue contre le Cancer and University of Strasbourg. B Frisch has received research grants from Centre National pour la Recherche Scientifique in France, Ligue contre le Cancer and University of Strasbourg and Alsace contre le cancer. S Fournel has received research grants from Centre National pour la Recherche Scientifique, in France, Ligue contre le Cancer and University of Strasbourg and Alsace contre le cancer. The authors have no other relevant affiliations or financial involvement with any organization or entity with a financial interest in or financial conflict with the subject matter or materials discussed in the manuscript apart from those disclosed. 


\title{
References
}

\author{
Reference annotations \\ * Of interest \\ ** Of considerable interest
}

[1] Dunn GP, Bruce AT, Ikeda $\mathrm{H}$, et al. Cancer immunoediting: from immunosurveillance to tumor escape. Nat. Immunol. 2002;3:991-998.

** The first review to propose a comprehensive model of cancer immunoediting based on a global insight into the historical and experimental basis of cancer immunosurveilance

[2] Teng MWL, Galon J, Fridman W-H, et al. From mice to humans: developments in cancer immunoediting. J. Clin. Invest. 2015;125:3338.

* Provides an updated description of tumor resistance to immune effector mechanisms in mice and humans, and in particular those targeting CD8+ T cells.

[3] Wherry EJ. T cell exhaustion. Nat. Immunol. 2011;12:492-499.

[4] Combadiere B, Liard C. Transcutaneous and intradermal vaccination. Human Vaccines. 2011;7:811-827.

[5] Kupper TS, Fuhlbrigge RC. Immune surveillance in the skin: mechanisms and clinical consequences. Nat. Rev. Immunol. 2004;4:211-222.

[6] Wosicka H, Cal K. Targeting to the hair follicles: current status and potential. J. Dermatol. Sci. 2010;57:83-89.

[7] Nishibu A, Ward BR, Jester JV, et al. Behavioral responses of epidermal Langerhans cells in situ to local pathological stimuli. J. Invest. Dermatol. 2006;126:787-796.

* Investigation of LCs ability to collect extra epidermal particles

[8] Henri S, Poulin LF, Tamoutounour S, et al. CD207+ CD103+ dermal dendritic cells cross-present keratinocyte-derived antigens irrespective of the presence of Langerhans cells. J. Exp. Med. 2010;207:189-206.

* Shows that LCs may not be mandatory for cross-presentation while providing an elegant characterization of skin DC subsets. 
[9] Yoshida K, Kubo A, Fujita $\mathrm{H}$, et al. Distinct behavior of human Langerhans cells and inflammatory dendritic epidermal cells at tight junctions in patients with atopic dermatitis. J. Allergy Clin. Immunol. 2014;134:856-864.

* Investigation of LCs ability to collect extra epidermal particles

[10] Ouchi T, Kubo A, Yokouchi M, et al. Langerhans cell antigen capture through tight junctions confers preemptive immunity in experimental staphylococcal scalded skin syndrome. J. Exp. Med. 2011;208:2607-2613.

[11] Hemmi $H$, Yoshino $M$, Yamazaki $H$, et al. Skin antigens in the steady state are trafficked to regional lymph nodes by transforming growth factor-beta1-dependent cells. Int. Immunol. 2001;13:695-704.

[12] Flacher V, Tripp CH, Stoitzner P, et al. Epidermal Langerhans cells rapidly capture and present antigens from C-type lectin-targeting antibodies deposited in the dermis. J. Invest. Dermatol. 2010;130:755-762.

** Reveals the importance of DC targeting in cutaneous delivery and how it increases uptake by

DCs

[13] Flacher V, Tripp CH, Haid B, et al. Skin langerin + dendritic cells transport intradermally injected anti-DEC-205 antibodies but are not essential for subsequent cytotoxic CD8+ T cell responses. J. Immunol. Baltim. Md 1950. 2012;188:2146-2155.

** Demonstrates that LCs are not essential for CD8+ T cell priming.

[14] Kissenpfennig A, Henri S, Dubois B, et al. Dynamics and Function of Langerhans Cells In Vivo. Immunity. 2005;22:643-654.

[15] Ritter U, Meißner A, Scheidig C, et al. CD8 $\alpha$ - and Langerin-negative dendritic cells, but not Langerhans cells, act as principal antigen-presenting cells in leishmaniasis. Eur. J. Immunol. 2004;34:1542-1550.

* Provides a complete dynamic view of LCs and dDCs under steady state and inflammatory conditions.

[16] Lee C-H, Chen J-S, Chiu H-C, et al. Differential activation behavior of dermal dendritic cells underlies the strain-specific Th1 responses to single epicutaneous immunization. J. Dermatol. Sci. 2016;84:248-257.

[17] Ebner S, Ehammer Z, Holzmann S, et al. Expression of C-type lectin receptors by subsets of dendritic cells in human skin. Int. Immunol. 2004;16:877-887.

[18] East L, Isacke CM. The mannose receptor family. Biochim. Biophys. Acta. 2002;1572:364-386.

[19] Cao T, Ueno H, Glaser C, et al. Both Langerhans cells and interstitial DC cross-present melanoma antigens and efficiently activate antigen-specific CTL. Eur. J. Immunol. 2007;37:2657-2667. 
[20] Stoitzner P, Tripp $\mathrm{CH}$, Eberhart A, et al. Langerhans cells cross-present antigen derived from skin. Proc. Natl. Acad. Sci. U. S. A. 2006;103:7783-7788.

[21] Idoyaga J, Cheong C, Suda K, et al. Cutting edge: langerin/CD207 receptor on dendritic cells mediates efficient antigen presentation on $\mathrm{MHCI}$ and II products in vivo. J. Immunol. Baltim. Md 1950. 2008;180:3647-3650.

[22] Kaplan $\mathrm{DH}$, Kissenpfennig A, Clausen BE. Insights into Langerhans cell function from Langerhans cell ablation models. Eur. J. Immunol. 2008;38:2369-2376.

[23] Kautz-Neu K, Noordegraaf $M$, Dinges $S$, et al. Langerhans cells are negative regulators of the anti-Leishmania response. J. Exp. Med. 2011;208:885-891.

[24] Bobr A, Olvera-Gomez I, Igyarto BZ, et al. Acute ablation of Langerhans cells enhances skin immune responses. J. Immunol. Baltim. Md 1950. 2010;185:4724.

[25] Bedoui S, Whitney PG, Waithman J, et al. Cross-presentation of viral and self antigens by skinderived CD103+ dendritic cells. Nat. Immunol. 2009;10:488-495.

[26] Flacher V, Tripp CH, Mairhofer DG, et al. Murine Langerin+ dermal dendritic cells prime CD8+ T cells while Langerhans cells induce cross-tolerance. EMBO Mol. Med. 2014;6:1191-1204.

[27] Dudziak D, Kamphorst AO, Heidkamp GF, et al. Differential antigen processing by dendritic cell subsets in vivo. Science. 2007;315:107-111.

[28] Bos JD, Meinardi MM. The 500 Dalton rule for the skin penetration of chemical compounds and drugs. Exp. Dermatol. 2000;9:165-169.

[29] Kumar S, Sahdev P, Perumal O, et al. Identification of a novel skin penetration enhancement peptide by phage display peptide library screening. Mol. Pharm. 2012;9:1320-1330.

[30] Afonin S, Frey A, Bayerl S, et al. The cell-penetrating peptide TAT(48-60) induces a non-lamellar phase in DMPC membranes. Chemphyschem Eur. J. Chem. Phys. Phys. Chem. 2006;7:21342142.

[31] Gautam A, Nanda JS, Samuel JS, et al. Topical Delivery of Protein and Peptide Using Novel Cell Penetrating Peptide IMT-P8. Sci. Rep. 2016;6:26278.

[32] Benson HAE. Transfersomes for transdermal drug delivery. Expert Opin. Drug Deliv. 2006;3:727737.

[33] Lee M-Y, Shin M-C, Yang VC. Transcutaneous antigen delivery system. BMB Rep. 2013;46:17-24.

[34] Pham QD, Björklund S, Engblom J, et al. Chemical penetration enhancers in stratum corneum Relation between molecular effects and barrier function. J. Controlled Release. 2016;232:175187. 
[35] Liu X, Grice JE, Lademann J, et al. Hair follicles contribute significantly to penetration through human skin only at times soon after application as a solvent deposited solid in man. Br. J. Clin. Pharmacol. 2011;72:768-774.

[36] Blume-Peytavi U, Vogt A. Human hair follicle: reservoir function and selective targeting. Br. J. Dermatol. 2011;165 Suppl 2:13-17.

[37] Kim Y-C, Prausnitz MR. Enabling skin vaccination using new delivery technologies. Drug Deliv. Transl. Res. 2011;1:7-12.

[38] Frerichs DM, Ellingsworth LR, Frech SA, et al. Controlled, single-step, stratum corneum disruption as a pretreatment for immunization via a patch. Vaccine. 2008;26:2782-2787.

[39] Sloat BR, Kiguchi K, Xiao G, et al. Transcutaneous DNA immunization following waxing-based hair depilation. J. Control. Release Off. J. Control. Release Soc. 2012;157:94-102.

[40] Engelke L, Winter G, Hook S, et al. Recent insights into cutaneous immunization: How to vaccinate via the skin. Vaccine. 2015;33:4663-4674.

[41] Nasr M, Abdel-Hamid S, Alyoussef AA. A highlight on lipid based nanocarriers for transcutaneous immunization. Curr. Pharm. Biotechnol. 2015;16:371-379.

[42] Esser ES, Romanyuk A, Vassilieva EV, et al. Tetanus vaccination with a dissolving microneedle patch confers protective immune responses in pregnancy. J. Control. Release Off. J. Control. Release Soc. 2016;236:47-56.

[43] van der Maaden K, Varypataki EM, Yu H, et al. Parameter optimization toward optimal microneedle-based dermal vaccination. Eur. J. Pharm. Sci. Off. J. Eur. Fed. Pharm. Sci. 2014;64:18-25.

[44] An M, Liu H. Dissolving Microneedle Arrays for Transdermal Delivery of Amphiphilic Vaccines. Small Weinh. Bergstr. Ger. 2017;13. [Epub ahead of print]

[45] Lee JW, Gadiraju P, Park J-H, et al. Microsecond thermal ablation of skin for transdermal drug delivery. J. Control. Release Off. J. Control. Release Soc. 2011;154:58-68.

[46] Witting $M$, Boreham A, Brodwolf $R$, et al. Interactions of hyaluronic Acid with the skin and implications for the dermal delivery of biomacromolecules. Mol. Pharm. 2015;12:1391-1401.

[47] Glenn GM, Villar CP, Flyer DC, et al. Safety and immunogenicity of an enterotoxigenic Escherichia coli vaccine patch containing heat-labile toxin: use of skin pretreatment to disrupt the stratum corneum. Infect. Immun. 2007;75:2163-2170.

[48] Vogt A, Hadam S, Deckert I, et al. Hair follicle targeting, penetration enhancement and Langerhans cell activation make cyanoacrylate skin surface stripping a promising delivery technique for transcutaneous immunization with large molecules and particle-based vaccines. Exp. Dermatol. 2015;24:73-75.

* $\quad$ Proves the feasibility of TC vaccination in humans using a CSSS method. 
[49] Ali AA, McCrudden CM, McCaffrey J, et al. DNA vaccination for cervical cancer; a novel technology platform of RALA mediated gene delivery via polymeric microneedles.

Nanomedicine Nanotechnol. Biol. Med. 2017;13:921-932.

[50] Tawde SA, Chablani L, Akalkotkar A, et al. Evaluation of microparticulate ovarian cancer vaccine via transdermal route of delivery. J. Controlled Release. 2016;235:147-154.

[51] Khong H, Overwijk WW. Adjuvants for peptide-based cancer vaccines. J. Immunother. Cancer. 2016;4:56.

[52] Kohli AK, Alpar HO. Potential use of nanoparticles for transcutaneous vaccine delivery: effect of particle size and charge. Int. J. Pharm. 2004;275:13-17.

[53] Larese Filon F, Mauro M, Adami G, et al. Nanoparticles skin absorption: New aspects for a safety profile evaluation. Regul. Toxicol. Pharmacol. 2015;72:310-322.

[54] Ascenso A, Raposo S, Batista C, et al. Development, characterization, and skin delivery studies of related ultradeformable vesicles: transfersomes, ethosomes, and transethosomes. Int. J.

Nanomedicine. 2015;10:5837-5851.

[55] Patzelt A, Richter $\mathrm{H}$, Knorr F, et al. Selective follicular targeting by modification of the particle sizes. J. Controlled Release. 2011;150:45-48.

[56] Xiang SD, Scholzen A, Minigo G, et al. Pathogen recognition and development of particulate vaccines: does size matter? Methods San Diego Calif. 2006;40:1-9.

[57] Foged C, Brodin B, Frokjaer S, et al. Particle size and surface charge affect particle uptake by human dendritic cells in an in vitro model. Int. J. Pharm. 2005;298:315-322.

[58] Vogt A, Combadiere B, Hadam S, et al. $40 \mathrm{~nm}$, but not 750 or 1,500 nm, nanoparticles enter epidermal CD1a+ cells after transcutaneous application on human skin. J. Invest. Dermatol. 2006;126:1316-1322.

[59] Jeanbart L, Ballester M, Titta A de, et al. Enhancing Efficacy of Anticancer Vaccines by Targeted Delivery to Tumor-Draining Lymph Nodes. Cancer Immunol. Res. 2014;2:436-447.

[60] Fan Y, Moon JJ. Nanoparticle Drug Delivery Systems Designed to Improve Cancer Vaccines and Immunotherapy. Vaccines. 2015;3:662-685.

[61] Reddy ST, Rehor A, Schmoekel HG, et al. In vivo targeting of dendritic cells in lymph nodes with poly(propylene sulfide) nanoparticles. J. Controlled Release. 2006;112:26-34.

[62] Reddy ST, van der Vlies AJ, Simeoni E, et al. Exploiting lymphatic transport and complement activation in nanoparticle vaccines. Nat. Biotechnol. 2007;25:1159-1164.

[63] Fifis T, Gamvrellis A, Crimeen-Irwin B, et al. Size-dependent immunogenicity: therapeutic and protective properties of nano-vaccines against tumors. J. Immunol. Baltim. Md 1950. 2004;173:3148-3154. 
[64] Mottram PL, Leong D, Crimeen-Irwin B, et al. Type 1 and 2 immunity following vaccination is influenced by nanoparticle size: formulation of a model vaccine for respiratory syncytial virus. Mol. Pharm. 2007;4:73-84.

* Demonstrates that particle size is a critical variable in immune response orientation

[65] Dragicevic-Curic N, Gräfe S, Gitter B, et al. Surface charged temoporfin-loaded flexible vesicles: in vitro skin penetration studies and stability. Int. J. Pharm. 2010;384:100-108.

[66] Wischke C, Borchert H-H, Zimmermann J, et al. Stable cationic microparticles for enhanced model antigen delivery to dendritic cells. J. Control. Release Off. J. Control. Release Soc. 2006;114:359-368.

[67] Nakanishi T, Kunisawa J, Hayashi A, et al. Positively charged liposome functions as an efficient immunoadjuvant in inducing cell-mediated immune response to soluble proteins. J. Control. Release Off. J. Control. Release Soc. 1999;61:233-240.

[68] Cui Z, Mumper RJ. Chitosan-based nanoparticles for topical genetic immunization. J. Control. Release Off. J. Control. Release Soc. 2001;75:409-419.

[69] Patzelt A, Mak WC, Jung S, et al. Do nanoparticles have a future in dermal drug delivery? J. Controlled Release. 2017;246:174-182.

[70] Ansaldi F, Orsi A, de Florentiis D, et al. Head-to-head comparison of an intradermal and a virosome influenza vaccine in patients over the age of 60: evaluation of immunogenicity, crossprotection, safety and tolerability. Hum. Vaccines Immunother. 2013;9:591-598.

* A clinical trial demonstrating the immunogenicity and the tolerability of a liposome-based influenza vaccine in elderly

[71] Levin Y, Kochba E, Shukarev G, et al. A phase 1, open-label, randomized study to compare the immunogenicity and safety of different administration routes and doses of virosomal influenza vaccine in elderly. Vaccine. 2016;34:5262-5272.

* Another successful clinical trial demonstrating the superiority of the skin for the delivery of liposome-based vaccines.

[72] Ambrosch F, Wiedermann G, Jonas S, et al. Immunogenicity and protectivity of a new liposomal hepatitis A vaccine. Vaccine. 1997;15:1209-1213.

* A successful clinical trial for the evaluation of a liposome-based Hepatitis A vaccine.

[73] Jain S, Patel N, Shah MK, et al. Recent Advances in Lipid-Based Vesicles and Particulate Carriers for Topical and Transdermal Application. J. Pharm. Sci. 2017;106:423-445.

[74] Fan $Y$, Zhang Q. Development of liposomal formulations: From concept to clinical investigations. Asian J. Pharm. Sci. 2013;8:81-87. 
[75] Schwendener RA. Liposomes as vaccine delivery systems: a review of the recent advances. Ther. Adv. Vaccines. 2014;2:159.

[76] Mezei M, Gulasekharam V. Liposomes--a selective drug delivery system for the topical route of administration. Lotion dosage form. Life Sci. 1980;26:1473-1477.

** The first report on the advantage of liposomes for the transcutaneous route.

[77] Elsayed MMA, Abdallah OY, Naggar VF, et al. Lipid vesicles for skin delivery of drugs: reviewing three decades of research. Int. J. Pharm. 2007;332:1-16.

[78] Cevc G, Blume G. Lipid vesicles penetrate into intact skin owing to the transdermal osmotic gradients and hydration force. Biochim. Biophys. Acta. 1992;1104:226-232.

** The original work that demonstrates and investigates the transfersomes ${ }^{\mathrm{TM}}$ ability to cross the skin barrier

[79] Matsuo K, Hirobe S, Okada N, et al. Frontiers of transcutaneous vaccination systems: novel technologies and devices for vaccine delivery. Vaccine. 2013;31:2403-2415.

[80] Wang J, Hu J, Li F, et al. Strong cellular and humoral immune responses induced by transcutaneous immunization with HBsAg DNA-cationic deformable liposome complex. Exp. Dermatol. 2007;16:724-729.

[81] Gupta V, Dhote V, Paul BN, et al. Development of novel topical drug delivery system containing cisplatin and imiquimod for dual therapy in cutaneous epithelial malignancy. J. Liposome Res. 2014;24:150-162.

[82] Tyagi RK, Garg NK, Dalai SK, et al. Transdermal immunization of P. falciparum surface antigen (MSP-119) via elastic liposomes confers robust immunogenicity. Hum. Vaccines Immunother. 2016;12:990-992.

[83] Rattanapak T, Young K, Rades $T$, et al. Comparative study of liposomes, transfersomes, ethosomes and cubosomes for transcutaneous immunisation: characterisation and in vitro skin penetration. J. Pharm. Pharmacol. 2012;64:1560-1569.

[84] Song CK, Balakrishnan P, Shim C-K, et al. A novel vesicular carrier, transethosome, for enhanced skin delivery of voriconazole: Characterization and in vitro/in vivo evaluation. Colloids Surf. B Biointerfaces. 2012;92:299-304.

[85] Espuelas S, Thumann C, Heurtault B, et al. Influence of ligand valency on the targeting of immature human dendritic cells by mannosylated liposomes. Bioconjug. Chem. 2008;19:23852393.

** Demonstrates an increased uptake of liposomes when they are targeted with ligands of suitable valency. 
[86] Thomann J-S, Heurtault B, Weidner S, et al. Antitumor activity of liposomal ErbB2/HER2 epitope peptide-based vaccine constructs incorporating TLR agonists and mannose receptor targeting. Biomaterials. 2011;32:4574-4583.

** An elegant work demonstrating that minimal peptide-expressing liposomal vaccines induce protective immunity against cancer

[87] Press Announcements - FDA Approves a Cellular Immunotherapy for Men with Advanced Prostate Cancer [Internet]. [cited 2017 Jan 22]. Available from: http://www.fda.gov/NewsEvents/Newsroom/PressAnnouncements/ucm210174.htm.

** The first cancer-vaccine improved by FDA for clinical use.

[88] Press Announcements - FDA approves first-of-its-kind product for the treatment of melanoma [Internet]. [cited 2017 Jan 22]. Available from:

http://www.fda.gov/NewsEvents/Newsroom/PressAnnouncements/ucm469571.htm.

** The second cancer vaccine improved by FDA for clinical use

[89] Karkada M, Berinstein NL, Mansour M. Therapeutic vaccines and cancer: focus on DPX-0907. Biol. Targets Ther. 2014;8:27.

[90] Berinstein NL, Karkada M, Morse MA, et al. First-in-man application of a novel therapeutic cancer vaccine formulation with the capacity to induce multi-functional T cell responses in ovarian, breast and prostate cancer patients. J. Transl. Med. 2012;10:156.

* A successful clinical trial of a cancer-specific liposomal based vaccine.

[91] Wurz GT, Kao C-J, Wolf M, et al. Tecemotide: an antigen-specific cancer immunotherapy. Hum. Vaccines Immunother. 2014;10:3383-3393.

[92] Davis ID, Chen W, Jackson H, et al. Recombinant NY-ESO-1 protein with ISCOMATRIX adjuvant induces broad integrated antibody and CD4+ and CD8+ T cell responses in humans. Proc. Natl. Acad. Sci. U. S. A. 2004;101:10697.

[93] Mitchell P, Thatcher N, Socinski MA, et al. Tecemotide in unresectable stage III non-small-cell lung cancer in the phase III START study: updated overall survival and biomarker analyses. Ann. Oncol. 2015;26:1134-1142.

[94] Nicholaou T, Chen W, Davis ID, et al. Immunoediting and persistence of antigen-specific immunity in patients who have previously been vaccinated with NY-ESO-1 protein formulated in ISCOMATRIX ${ }^{\text {TM }}$. Cancer Immunol. Immunother. 2011;60:1625.

[95] Nicholaou T, Ebert LM, Davis ID, et al. Regulatory T-Cell-Mediated Attenuation of T-Cell Responses to the NY-ESO-1 ISCOMATRIX Vaccine in Patients with Advanced Malignant Melanoma. Clin. Cancer Res. 2009;15:2166-2173. 
[96] Chen J-L, Dawoodji A, Tarlton A, et al. NY-ESO-1 specific antibody and cellular responses in melanoma patients primed with NY-ESO-1 protein in ISCOMATRIX and boosted with recombinant NY-ESO-1 fowlpox virus. Int. J. Cancer. 2015;136:E590-E601.

[97] Nemunaitis J, Jahan T, Ross $\mathrm{H}$, et al. Phase $1 / 2$ trial of autologous tumor mixed with an allogeneic GVAX vaccine in advanced-stage non-small-cell lung cancer. Cancer Gene Ther. 2006;13:555-562.

[98] Sabado RL, Pavlick A, Gnjatic S, et al. Resiquimod as an immunologic adjuvant for NY-ESO-1 protein vaccination in patients with high-risk melanoma. Cancer Immunol. Res. 2015;3:278-287.

** A successful clinical trial showing that transcutaneous administration of a potent adjuvants is crucial for the induction of tumor-specific $C D 8+T$ cell responses against protein antigens.

[99] Adams S, O'Neill DW, Nonaka D, et al. Immunization of malignant melanoma patients with fulllength NY-ESO-1 protein using TLR7 agonist imiquimod as vaccine adjuvant. J. Immunol. Baltim. Md 1950. 2008;181:776-784.

[100] Burkhardt UE, Hainz U, Stevenson K, et al. Autologous CLL cell vaccination early after transplant induces leukemia-specific T cells. J. Clin. Invest. 2013;123:3756-3765.

[101] Dhodapkar MV, Sznol M, Zhao B, et al. Induction of antigen-specific immunity with a vaccine targeting NY-ESO-1 to the dendritic cell receptor DEC-205. Sci. Transl. Med. 2014;6:232ra51.

[102] Fujiyama T, Oze I, Yagi H, et al. Induction of cytotoxic T cells as a novel independent survival factor in malignant melanoma with percutaneous peptide immunization. J. Dermatol. Sci. 2014;75:43-48.

** The first and only successful clinical trial where the vaccine peptides and adjuvant are both administred transcutaneously.

[103] Iwama T, Uchida T, Sawada Y, et al. Vaccination with liposome-coupled glypican-3-derived epitope peptide stimulates cytotoxic T lymphocytes and inhibits GPC3-expressing tumor growth in mice. Biochem. Biophys. Res. Commun. 2016;469:138-143.

[104] Shariat S, Badiee A, Jalali SA, et al. P5 HER2/neu-derived peptide conjugated to liposomes containing MPL adjuvant as an effective prophylactic vaccine formulation for breast cancer. Cancer Lett. 2014;355:54-60.

[105] Kakhi Z, Frisch B, Heurtault B, et al. Liposomal constructs for antitumoral vaccination by the nasal route. Biochimie. 2016;130:14-22.

** Demonstrates the ability of well-designed liposome-based vaccines to induce a protective tumor specific response after non invasive administration.

[106] Kakhi Z, Frisch B, Bourel-Bonnet L, et al. Airway administration of a highly versatile peptidebased liposomal construct for local and distant antitumoral vaccination. Int. J. Pharm. 2015;496:1047-1056. 
** Demonstrates the ability of well-designed liposome-based vaccines to induce a protective tumor specific response after non invasive administration.

[107] Karkada M, Weir GM, Quinton T, et al. A liposome-based platform, VacciMax ${ }^{\circledR}$, and its modified water-free platform DepoVax ${ }^{\mathrm{TM}}$ enhance efficacy of in vivo nucleic acid delivery. Vaccine. 2010;28:6176-6182.

[108] Butts C, Socinski MA, Mitchell PL, et al. Tecemotide (L-BLP25) versus placebo after chemoradiotherapy for stage III non-small-cell lung cancer (START): a randomised, double-blind, phase 3 trial. Lancet Oncol. 2014;15:59-68.

** A large phase III clinical trial for the evaluation of one of the first liposome-based cancer vaccines

Figure 1: Key steps of a protective adaptive tumor-specific immune response. (1) Tumor associated antigens (TAAs) are expressed by tumor cells, presented on MHC class I molecules and released from dying cells. (2) Damage associated molecular patterns (DAMPs) are also released from stressed or dying cells, and meet their specific receptors on DCs. (3) TAAs are internalized by DCs and cross-presented on MHC class I and class II molecules. (4) TAA-specific CD4+ and CD8+ T cells are primed by DCs. CD4+ T lymphocytes differentiate into Th1 cells and primed CD8+ lymphocytes differentiate into CTLs. (5) Effector cells migrate to the tumor where (6) CTL recognize and kill TAA-expressing cells. MHC: major histocompatibility complex, TAA; Tumor associated antigen, DAMP: damage associated patterns, DC: dendritic cell, PRR: pattern recognition receptor, TCR: T cell receptor, CTL: Cytotoxic T lymphocyte.
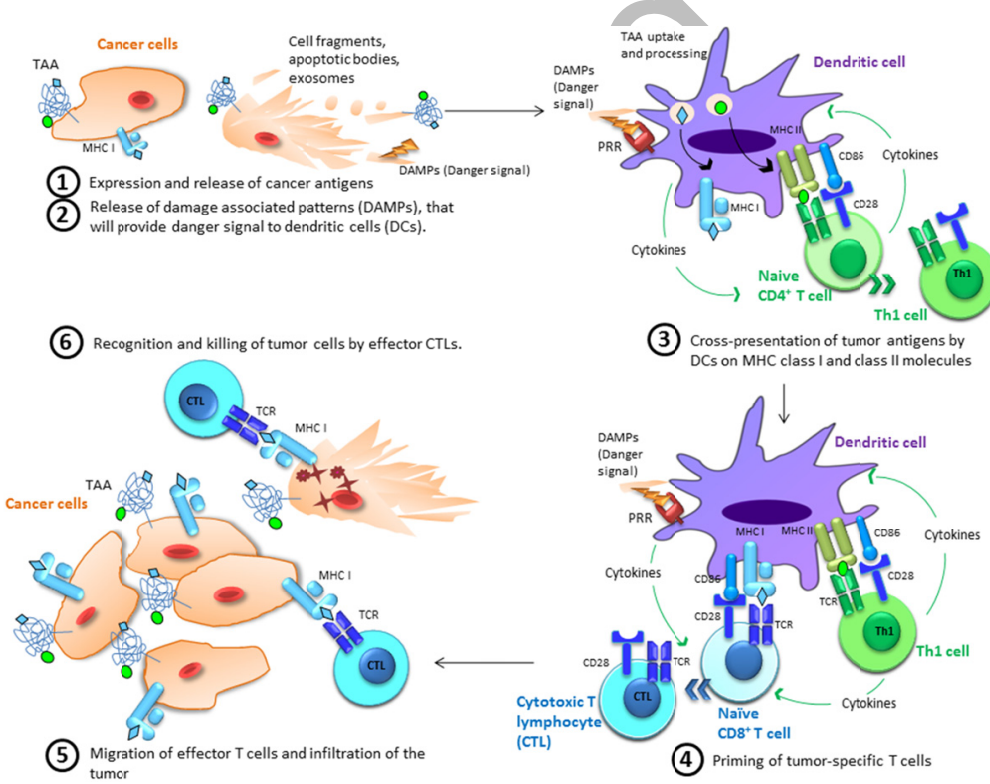
Figure 2: Skin layers, skin dendritic cells and their corresponding markers.

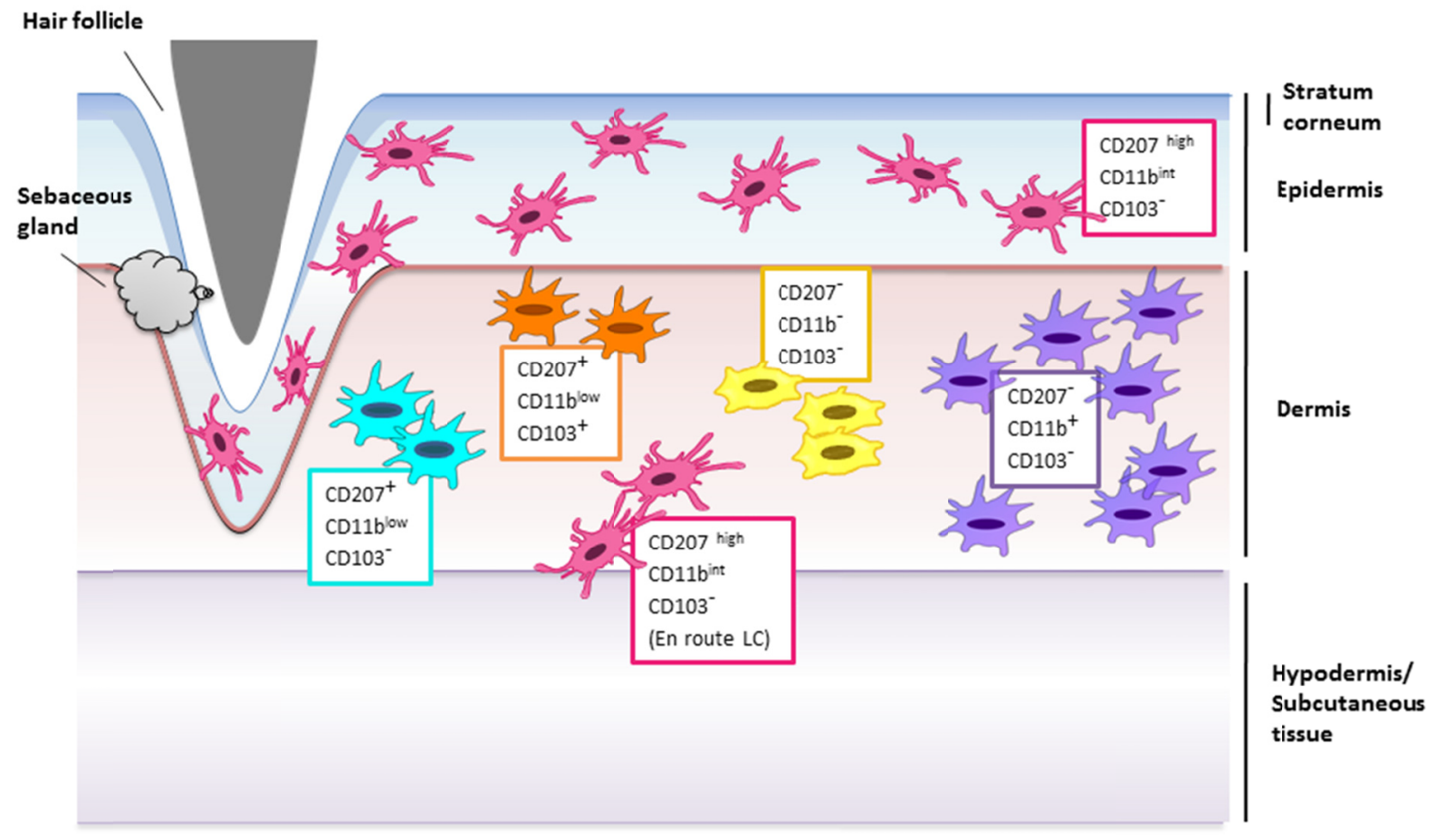


Figure 3. (a) Transcutaneous passage involves transepidermal and transfollicular ports. (b) Schematic representation of strategies of transcutaneous vaccination: jet injection of liquid and powder vaccines, thermal poration, sonoporation, electroporation, microneedles, permeation enhancers, nanoparticles and removal of stratum corneum and/or follicles content.

(a)

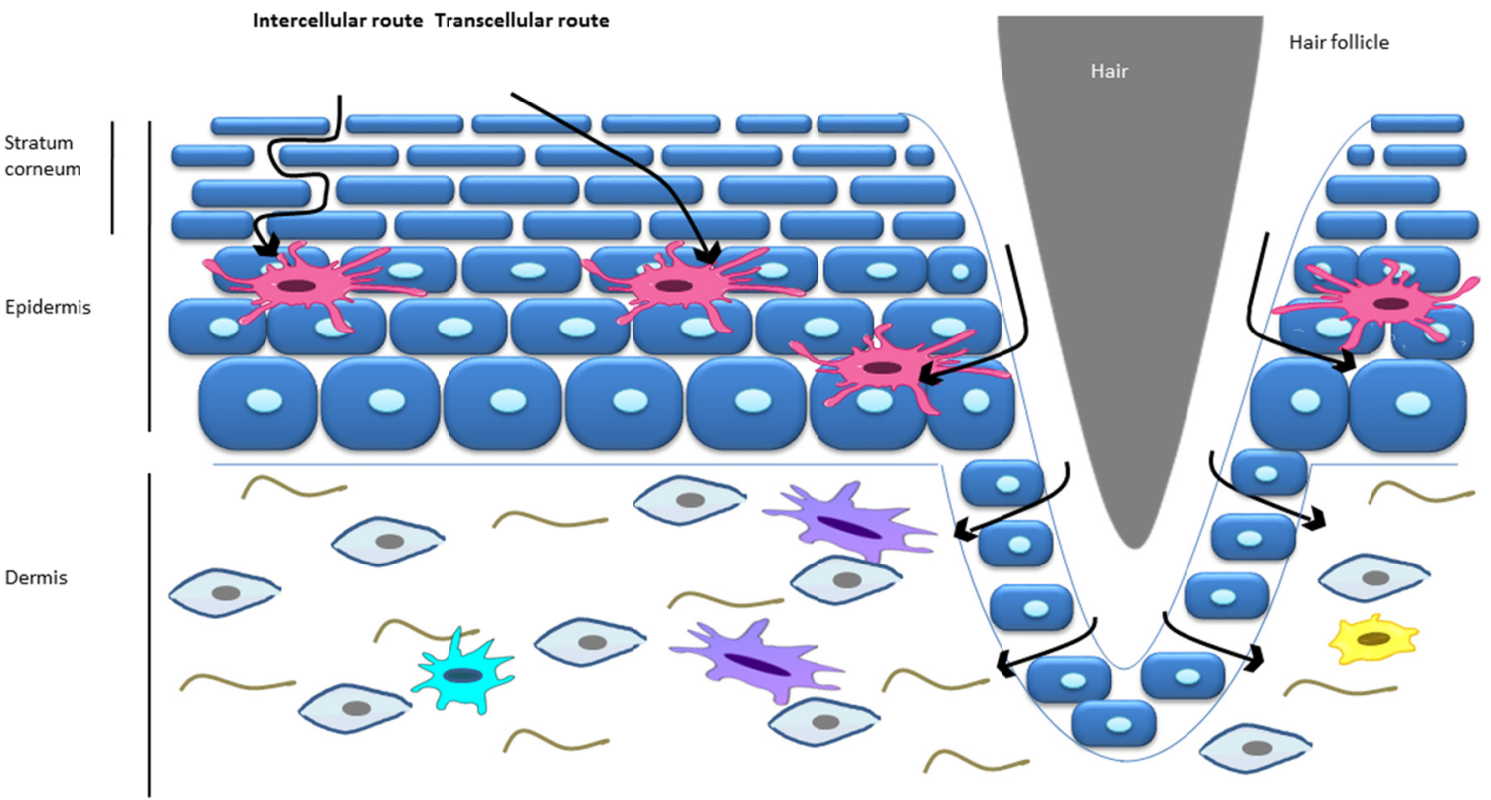

(b)

\begin{tabular}{|c|c|c|c|c|c|}
\hline let injectors & $\begin{array}{l}\text { Thermal poration } \\
\text { Sonoporation } \\
\text { Electroporation }\end{array}$ & Microneedles & $\begin{array}{l}\text { Permeation } \\
\text { enhancers }\end{array}$ & Nanoparticles & $\begin{array}{l}\text { Removal of stratum } \\
\text { corneum and/or follic } \\
\text { content }\end{array}$ \\
\hline a & $\begin{array}{l}\text { Electrical energy/ } \\
\text { Radiofrequency/Laser }\end{array}$ & & $\begin{array}{c}\text { DMSO/ Oleic acid } \\
\text { chains }\end{array}$ & & $\begin{array}{l}\text { CSSS/Tape } \\
\text { stripping }\end{array}$ \\
\hline
\end{tabular}

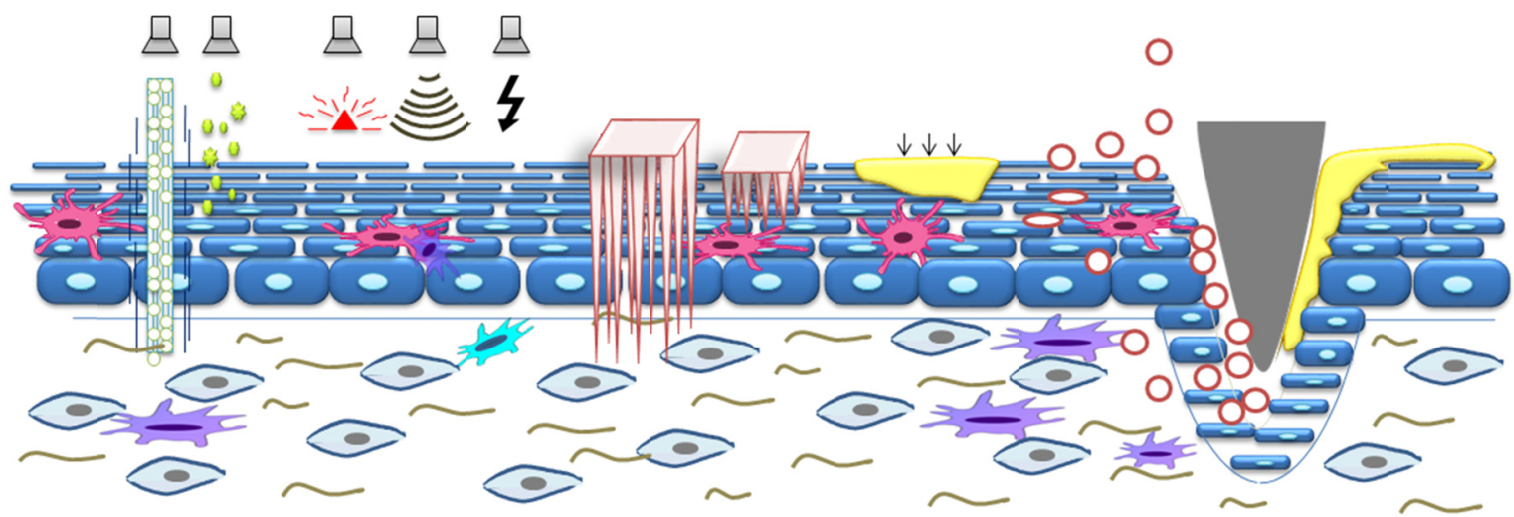


Figure 4: Interaction of active compounds with liposomes. Due to the physicochemical properties of liposomes, active compounds can either be incorporated in their core, or included in their surrounding layer(s), or be attached or adsorbed on their surface

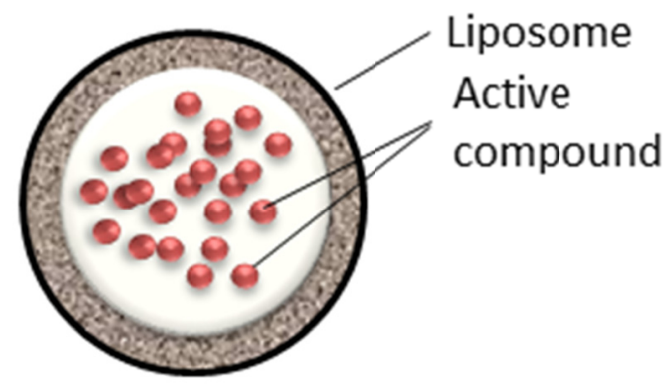

Encapsulation

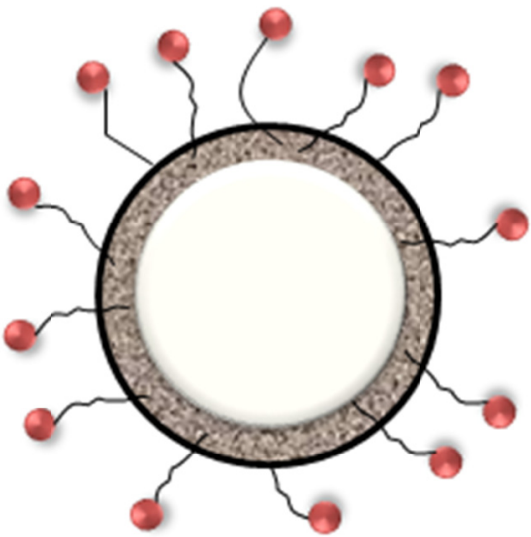

Presentation on the surface using anchors

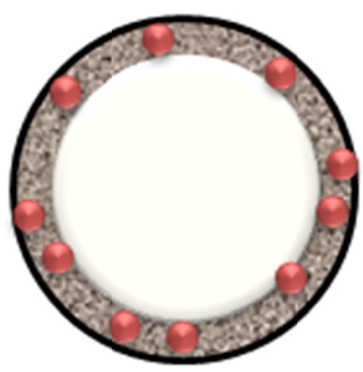

Integration in lipid bilayers

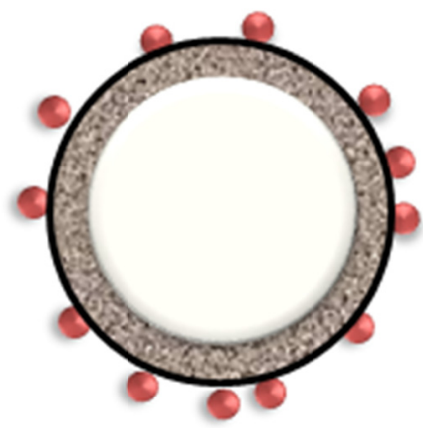

Adsorption on lipid bilayers 
Figure 5: Influence of particle diameter on skin barrier crossing (transepidermal and transfollicular passage), drainage, uptake by dendritic cells (DCs) and immunogenicity. Other physicochemical parameters such as hydrophily and zeta potential can also affect particle behavior and properties.

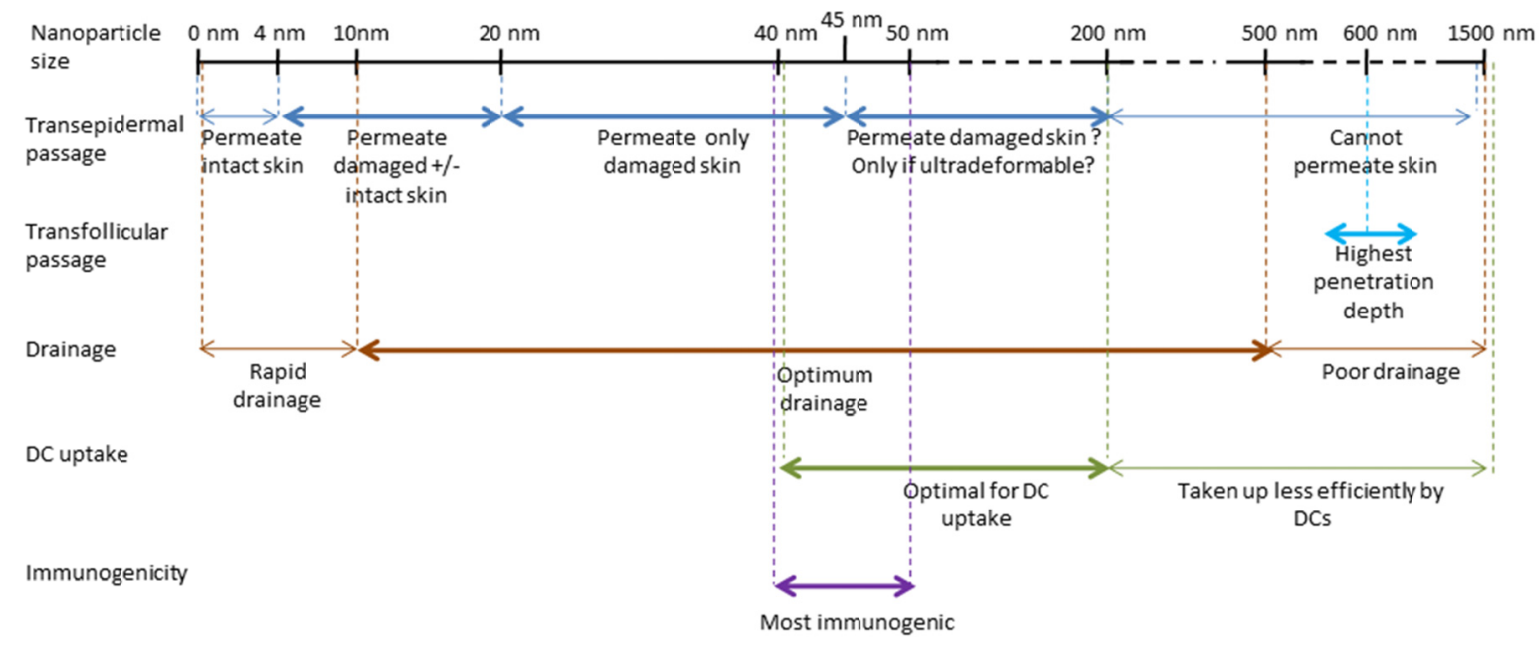

Table 1: Tumor cells escape mechanisms according to Teng et al, 2015 [2].

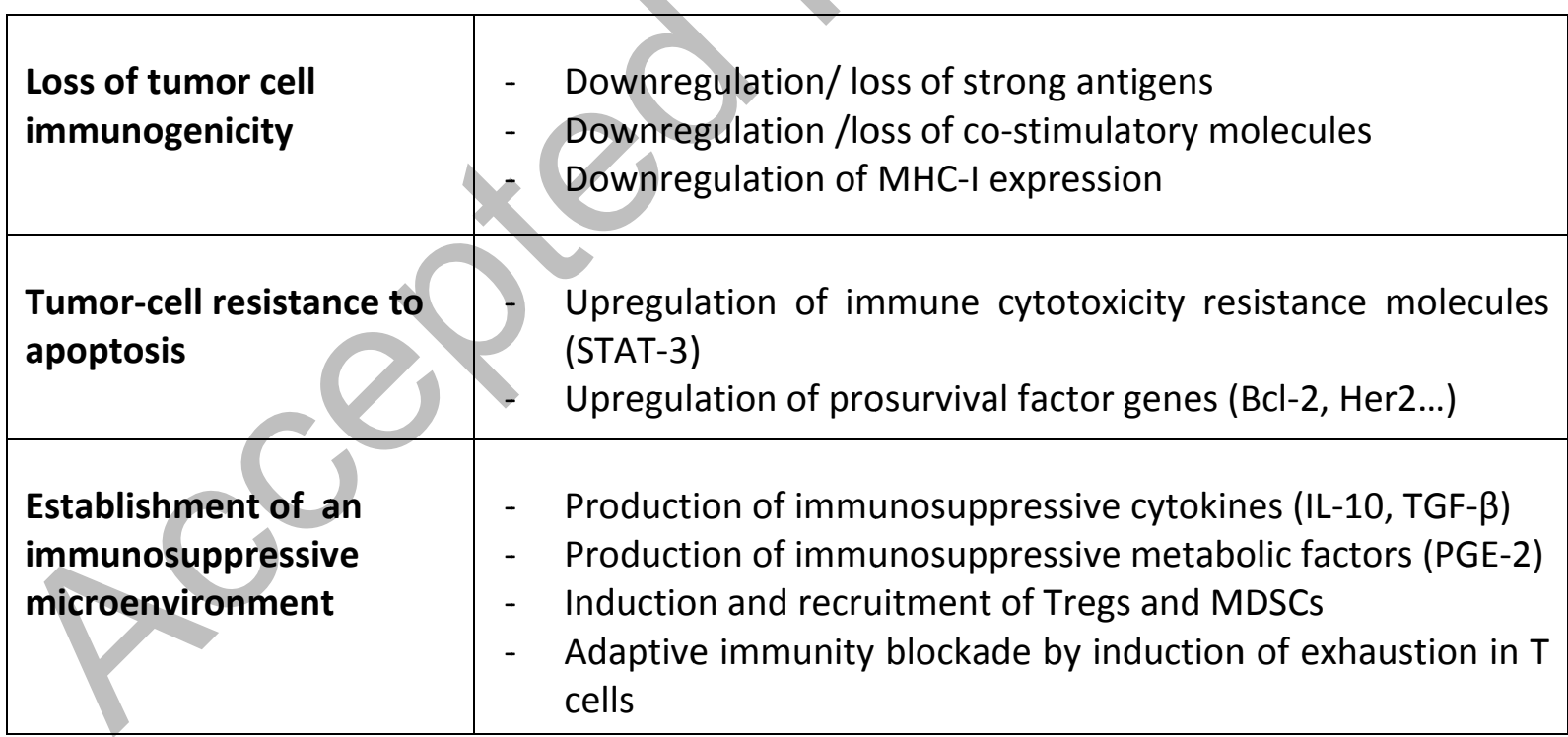

MHC: Major histocompatibility complex; STAT-3: Signal Transducer and Activator of Transcription-3; Bcl2: as B-cell lymphoma-2; Her2: Human epidermal growth factor receptor 2; IL-10: Interleukin-10; TGF- $\beta$ : Tumor growth factor- $\beta$; PGE-2: prostaglandin E2; Treg: Regulatory T cells; MDSC: myeloid-derived suppressor cells. 
Table 2: Role of skin DCs in immune activation.

\begin{tabular}{|c|c|c|c|}
\hline Cell type & $\begin{array}{l}\text { Phenotypic } \\
\text { markers }\end{array}$ & Role in cellular immunity & Reference \\
\hline Langerhans cells & $\begin{array}{l}\text { CD207 } \\
\text { CD11 }{ }^{\text {high }} \\
\text { CD103 }^{-}\end{array}$ & $\begin{array}{l}\text { In vitro and in vivo induction of } \mathrm{T} \\
\text { cell proliferation } \\
\text { Induction of antigen-loaded cells } \\
\text { killing by CD8+ T cells }\end{array}$ & $\begin{array}{c}{[14,22,23]} \\
{[22]}\end{array}$ \\
\hline \multirow{3}{*}{$\begin{array}{l}\text { Dermal dendritic } \\
\text { cells }\end{array}$} & $\begin{array}{l}{\mathrm{CD} 207^{+}}^{\text {low }} \\
\mathrm{CD} 11 \mathrm{~b}^{\text {low }} \\
\mathrm{CD} 103^{-} \\
\mathrm{CD} 207^{+} \\
\mathrm{CD}_{11 b^{\text {low }}} \\
\mathrm{CD}_{103^{+}}\end{array}$ & $\begin{array}{l}\mathrm{CD}_{207^{+}} \mathrm{dDCs} \text { are particularly } \\
\text { potent in inducing a } \mathrm{CD} 8+\text { response }\end{array}$ & [15] \\
\hline & $\begin{array}{l}\mathrm{CD}^{207^{-}} \\
{\mathrm{CD} 11 \mathrm{~b}^{+}}^{+} \\
\mathrm{CD} 103^{-}\end{array}$ & \multirow[b]{2}{*}{ Induction of a CD4+ T cell response } & \multirow{2}{*}{ [15] } \\
\hline & $\begin{array}{l}\mathrm{CD}^{207^{-}} \\
\mathrm{CD}^{-} 1 \mathrm{~b}^{-} \\
\mathrm{CD}^{-} 03^{-}\end{array}$ & & \\
\hline
\end{tabular}

Int: intermediate

Table 3: Skin barrier disruption techniques.

\begin{tabular}{|c|c|c|c|}
\hline $\begin{array}{l}\text { Physical barrier } \\
\text { disruption technique }\end{array}$ & Process & Properties & References \\
\hline $\begin{array}{l}\text { Abrasion, waxing, } \\
\text { skin surface } \\
\text { stripping }\end{array}$ & Removal of stratum corneum & $\begin{array}{l}\text { Improve the immunogenicity } \\
\text { of applied vaccines } \\
\text { Uncomfortable when a high } \\
\text { number of strikes is needed }\end{array}$ & {$[4,37-39]$} \\
\hline Jet injectors & $\begin{array}{l}\text { Skin piercing with } \\
\text { compressed gas hitting the } \\
\text { skin with high velocity }\end{array}$ & $\begin{array}{l}\text { Delivery of liquid or powder } \\
\text { vaccines } \\
\text { May cause pain, bruising, and } \\
\text { application-site burning }\end{array}$ & {$[40,41]$} \\
\hline
\end{tabular}




\begin{tabular}{|c|c|c|c|}
\hline Microneedles & $\begin{array}{l}\text { Hollow or vaccine-coated } \\
\text { solid or dissolvable needles }\end{array}$ & Painless and Self-administered & {$[42-44]$} \\
\hline $\begin{array}{l}\text { Thermal } \\
\text { microporation or } \\
\text { thermal ablation }\end{array}$ & $\begin{array}{l}\text { Stratum corneum } \\
\text { vaporization with highly } \\
\text { focused thermal energy. } \\
\text { Induction of micron-sized } \\
\text { pores. }\end{array}$ & $\begin{array}{l}\text { Delivery of hydrophilic molecules } \\
\text { Induce activation and migration } \\
\text { of LCs }\end{array}$ & {$[37,45]$} \\
\hline $\begin{array}{l}\text { Sonoporation/ } \\
\text { electroporation }\end{array}$ & $\begin{array}{l}\text { Transient molecular-scale } \\
\text { disruption of the cellular } \\
\text { plasma membrane }\end{array}$ & $\begin{array}{l}\text { Expensive and needs } \\
\text { supply }\end{array}$ & {$[37,41]$} \\
\hline $\begin{array}{l}\text { Permeation } \\
\text { enhancers, addition } \\
\text { of polar chains, } \\
\text { conjugation to cell } \\
\text { penetrating } \\
\text { peptides }\end{array}$ & $\begin{array}{l}\text { Molecular interactions with } \\
\text { plasma membranes }\end{array}$ & $\begin{array}{l}\text { Increase the permeability to } \\
\text { macromolecules }\end{array}$ & {$[31,46]$} \\
\hline
\end{tabular}

Table 4: Examples of the most promising cancer vaccines involving lipid-based carriers.

\begin{tabular}{|c|c|c|c|c|c|c|c|}
\hline $\begin{array}{l}\text { Vesicle } \\
\text { type }\end{array}$ & Vaccine & Adjuvant & $\begin{array}{l}\text { Administratio } \\
\mathrm{n} \text { route }\end{array}$ & $\begin{array}{l}\text { Traget } \\
\text { cancer } \\
\text { type }\end{array}$ & $\begin{array}{l}\text { Clinica } \\
\text { I trial }\end{array}$ & Study outcome & REF \\
\hline \multirow[t]{2}{*}{$\begin{array}{l}\text { Liposom } \\
\text { e }\end{array}$} & $\begin{array}{l}\text { Depovax } \\
\text { (DPX)-0907: } \\
7 \text { TAA- } \\
\text { derived TC } \\
\text { peptides, } \\
\text { and a } \\
\text { tetanus } \\
\text { toxoid- } \\
\text { derived Th } \\
\text { epitope }\end{array}$ & $\begin{array}{l}\text { Polynucleotid } \\
\text { e based- } \\
\text { adjuvant }\end{array}$ & SC & $\begin{array}{l}\text { Breast, } \\
\text { ovarian, } \\
\text { prostate } \\
\text { cancer }\end{array}$ & $\begin{array}{l}\text { Phase } \\
1\end{array}$ & $\begin{array}{l}\text { - Specific CD8 } \\
\text { T cell } \\
\text { response } \\
(61 \% \\
\text { response } \\
\text { rate) } \\
\text { - Specific T } \\
\text { cell memory }\end{array}$ & [82] \\
\hline & $\begin{array}{l}\text { BLP-25, or } \\
\text { Tecemotide, } \\
\text { or Stimuvax } \\
\text { : BP } 25 \\
\text { peptide of } \\
\text { the MUC1 } \\
\text { protein }\end{array}$ & $\begin{array}{l}\text { MPLA (TLR } 4 \\
\text { agonist) }\end{array}$ & SC & $\begin{array}{l}\text { Non- } \\
\text { small-cell } \\
\text { lung } \\
\text { cancer }\end{array}$ & $\begin{array}{l}\text { Phase } \\
\text { III }\end{array}$ & $\begin{array}{l}\text { - MUC1 } \\
\text { proliferative } \\
\text { T cell } \\
\text { response } \\
\text { - No survival } \\
\text { benefits, } \\
\text { unless with } \\
\text { concurrent }\end{array}$ & $\begin{array}{l}{[83,85,100} \\
]\end{array}$ \\
\hline
\end{tabular}




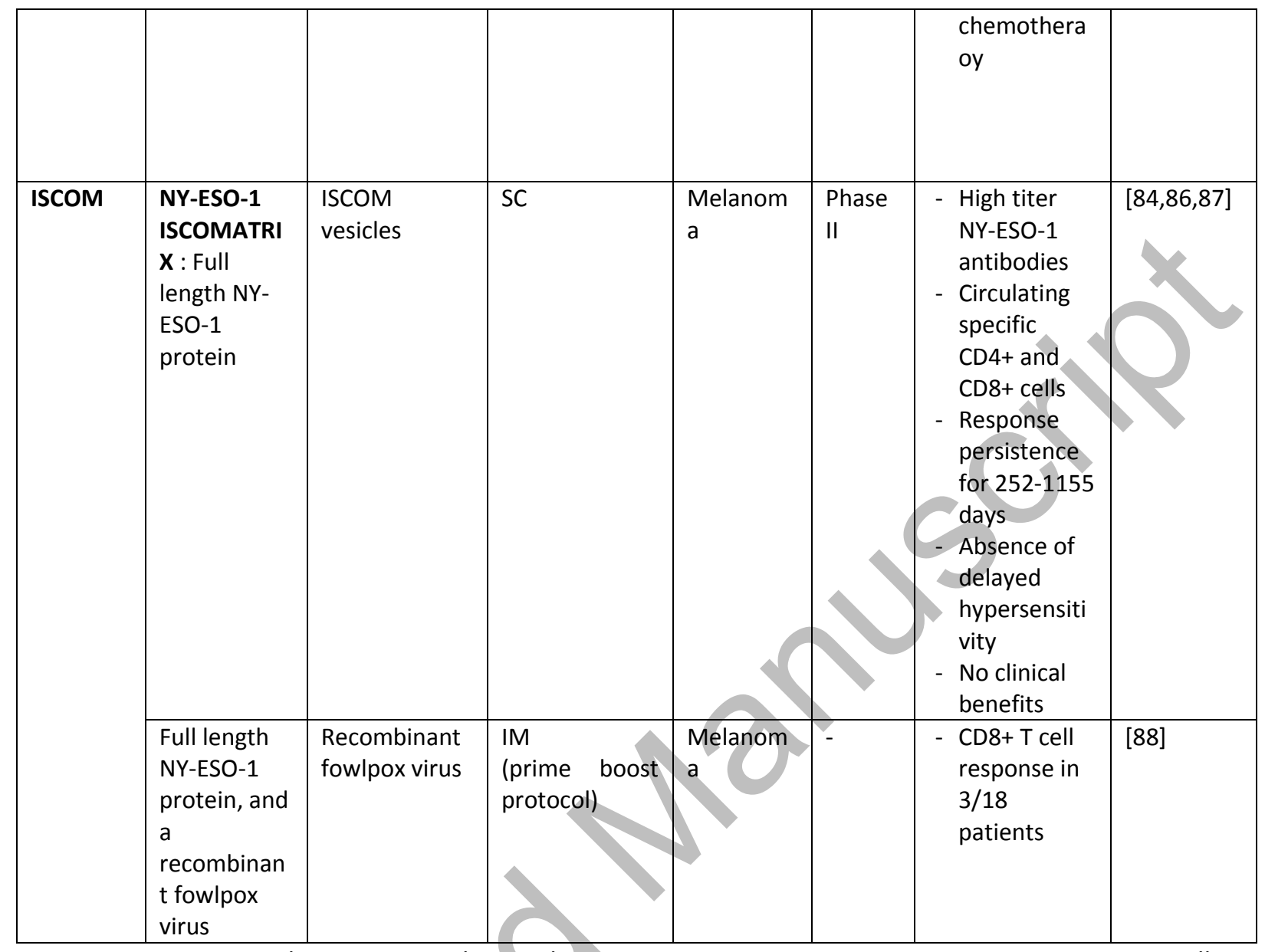

TAA: tumor-associated antigen; HLA: human leucocyte antigen; SC: subcutaneous; MUC: Mucin; TLR: TollLike Receptor; MPLA: Monophophoryl Lipid A; ISCOM: Immune stimulating complex; IM: intramuscular

Table 5: The most promising cancer vaccines involving the TC administration route.

\begin{tabular}{|c|c|c|c|c|c|c|}
\hline Vaccine & Adjuvant & $\begin{array}{l}\text { Administration } \\
\text { route }\end{array}$ & $\begin{array}{l}\text { Traget cancer } \\
\text { type }\end{array}$ & $\begin{array}{l}\text { Clinical } \\
\text { trial }\end{array}$ & Study outcome & REF \\
\hline $\begin{array}{l}\text { CDX-1401 : full } \\
\text { length NY-ESO-1- } \\
\text { protein, fused to } \\
\text { anti DEC-2015 mAb }\end{array}$ & $\begin{array}{l}\text { Resiquimod (TLR } \\
7 / 8 \text { agonist) } \\
\text { Or } \\
\text { Poly ICLC (TLR } 3 \\
\text { agonist) }\end{array}$ & $\begin{array}{l}\text { Various } \\
\text { combinations } \\
\text { of TC and SC } \\
\text { routes }\end{array}$ & $\begin{array}{l}\text { melanoma, } \\
\text { sarcoma, } \\
\text { ovarian } \\
\text { cancer and } \\
\text { others }\end{array}$ & Phase I & $\begin{array}{l}\text { - NY-ESO-1-specific cellular } \\
\text { immunity of } 56 \% \text { of the } \\
\text { patients } \\
\text { - Disease stabilization in } \\
13 / 56 \text { patients, and } \\
\text { occasional disease } \\
\text { regression }\end{array}$ & [93] \\
\hline \multirow[t]{2}{*}{$\begin{array}{l}\text { Full length NY-ESO- } \\
1 \text { protein }\end{array}$} & $\begin{array}{l}\text { Imiquimod (TLR } \\
7 \text { agonist) }\end{array}$ & $\begin{array}{l}\text { Protein (ID) and } \\
\text { imiquimod (TC) }\end{array}$ & Melanoma & Phase I & $\begin{array}{l}\text { - NY-ESO-1 specific antibodies } \\
\text { - Absence of CD8+ response }\end{array}$ & [91] \\
\hline & $\begin{array}{l}\text { Resiquimod (TLR } \\
7 / 8 \text { agonist) and } \\
\text { montanide }\end{array}$ & $\begin{array}{l}\text { montanide- } \\
\text { emulsfied } \\
\text { protein (ID) and } \\
\text { resiquimod (TC) }\end{array}$ & Melanoma & Phase II & $\begin{array}{l}\text { - NY-ESO-1 specific antibodies } \\
\text { in all subjects } \\
\text { - Specific CD4+ T cells and } \\
\text { CD8+ T cells (in } 3 / 12 \\
\text { subjects) }\end{array}$ & [90] \\
\hline
\end{tabular}




\begin{tabular}{|l|l|l|l|l|l|}
\hline $\begin{array}{l}\text { Tumor-derived } \\
\text { peptides/DMSO }\end{array}$ & $\begin{array}{l}\text { Absence of } \\
\text { adjuvant } \\
\text { molecule- Tape } \\
\text { tripping for skin- } \\
\text { barrier } \\
\text { disruption }\end{array}$ & Melanoma & Phase I & - Extension of overall survival & [94] \\
\hline
\end{tabular}

mAb: monoclonal antibody; TLR: Toll-Like Receptor, Poly-ICLC: Polyinosinic-Polycytidylic acid with

Polylysine and Carboxymethylcellulose; TC: transcutaneous; SC: subcutaneous; ID: intradermal, DMSO:

Dimethylsulfoxide 